Path dependency and recombinant exploration:

How established firms can outperform in the creation of technological breakthroughs

Sam Arts

DEPARTMENT OF MANAGERIAL ECONOMICS, STRATEGY AND INNOVATION (MSI) 


\title{
Path Dependency and Recombinant Exploration: How Established Firms Can Outperform in the Creation of Technological Breakthroughs
}

\author{
Sam Arts \\ KU Leuven and FWO \\ sam.arts@kuleuven.be
}

\begin{abstract}
How can established firms create technology breakthroughs? Adopting an evolutionary perspective of corporate $R \& D$, we argue and show that firms which leverage knowledge, skills and technology accumulated from prior R\&D by brokering technology subfields of established competence with less or unfamiliar subfields are most likely to create breakthroughs. Using patent stocks to measure firms' capabilities in each technology subfield at a particular moment in time, we find patents recombining technology subfields for the first time in history are most likely pioneered by new firms. Nevertheless, technological breakthroughs originating from brokering disconnected subfields are most likely pioneered by firms with most prior knowledge, skills and technology and capable of recombining them in a novel way.
\end{abstract}

Keywords: technological breakthrough, recombination, exploration, brokering, path-dependency 


\section{Introduction}

"Innovative firms can succeed not by breaking free from constraints of the past but instead by harnessing the past in powerful new ways" (Hargadon, 2003a, p. xii)

If and how can established firms create technological breakthroughs by leveraging their knowledge, skills and technology accumulated from prior R\&D rather than by developing new resources and capabilities from scratch? In this paper, we study one particular exploration strategy identified in the literature as key for fostering the creation of breakthroughs, namely creating new recombinations of familiar technological components or subfields ${ }^{1}$ (Fleming, 2001; Hargadon, 2003a). In particular, we are interested in whether technology leaders, i.e. companies with a strong competitive position from prior $R \& D$, can leverage these capabilities in order to pioneer breakthroughs.

Technology evolves through long periods of incremental change disrupted by technological breakthroughs, offering order-of-magnitude improvements in the price versus performance ratio over existing technology (Tushman and Anderson, 1986). Technological breakthroughs are a key determinant of entrepreneurial activity, creative destruction and economic growth (Schumpeter, 1942). Companies pioneering such breakthroughs are found to grow at a much faster rate (Tushman and Anderson, 1986).

Many studies argue and illustrate how large established firms typically struggle to create breakthrough inventions because they lack the incentives and because their R\&D tends to be path or history dependent causing firms to fall into learning or competency traps (e.g. Henderson, 1993; Ahuja and Lampert, 2001). Breakthroughs are generally considered competencedestroying to the extent that they are based on science and engineering principles unfamiliar for incumbents, rendering obsolete knowledge, capabilities and technology accumulated from prior R\&D (Tushman and Anderson, 1986; Henderson and Clark, 1990; Hill and Rothaermel, 2003). Given that industrial R\&D is path dependent (Helfat, 1994; Stuart and Podolny, 1996), established firms predominantly create new technology in areas of established competence rather than in unfamiliar and emerging technology subfields. As such, the standard model of creative

\footnotetext{
${ }^{1}$ Fleming (2001) argues the technology subclasses of a patent reflect the technological components of the patented technology. In this paper, technological components and subfields are used interchangeably.
} 
destruction predicts entrants to introduce breakthrough innovations causing industry leaders to go into decline (Schumpeter, 1934; Cooper and Schendel, 1976; Foster, 1986).

Because large established firms are responsible for the large majority of all R\&D investments worldwide, identifying strategies how these firms can foster the creation of breakthroughs might stimulate significant growth in private and social value (Ahuja and Lampert, 2001). Starting from the observation that established firms play a more important role in the discovery of breakthroughs than initially recognized (Methe et al, 1997), the focus in the literature shifted towards understanding how established firms can counteract the liabilities of learning and competency traps as to invent breakthroughs. In general, firms are advised to go beyond fields of established competence by for instance investing R\&D in unfamiliar and emerging technology fields (Foster, 1986; Ahuja and Lampert, 2001; Kotha et al, 2011) or by searching for technological antecedents developed outside the firm or from unfamiliar technology fields (Rosenkopf and Nerkar, 2001). Yet, creating new business opportunities from internal development is only advisable as long as it involves familiar technology, i.e. in case the required knowledge and expertise exist inside the firm (Roberts and Berry, 1983). Kogut and Zander (1992) argue that in case a company moves away from its exiting knowledge and competence base, the likelihood of successfully innovating becomes very small. Others discuss how Schumpeterian innovation relies on the ability of the firm to create novel combinations of firm resources and capabilities (Galunic and Rodan, 1998).

Core capabilities are frequently associated with knowledge, skills and technology from R\&D (Prahalad and Hamel, 1990; Leonard-Barton, 1992). These resources and capabilities are mainly tacit in nature and accumulate in a path dependent fashion making it difficult to replace or acquire them when needed (Helfat, 1994; Garud and Nayar, 1994). Besides the seminal work by Tushman and Anderson (1986), the literature has remained rather silent about if and how capabilities from prior $\mathrm{R} \& \mathrm{D}$ might be supportive rather than restrictive for the creation of breakthroughs in the future. Better understanding how large established firms can redeploy knowledge, skills and technology from prior R\&D is important given that competence-enhancing technological breakthroughs, which build on prior knowledge and capabilities, are more common than competence-destroying breakthroughs, which render established capabilities and technology obsolete (Tushman and Anderson, 1986). This type of breakthroughs is most likely pioneered by 
established firms with strong technological capabilities. As such, a key challenge for established firms is to create breakthroughs and expand in new and uncertain markets while at the same time exploiting their resources and capabilities from prior R\&D.

We start from the idea that technological breakthrough most likely originate from new recombinations of very familiar technology subfields or components (Fleming, 2001). Hargadon (2003a, 2004) discusses how brokering disconnected but pre-existing technological components led to many of the technological revolutions of the past century and a half including the light bulb and the reebok pump shoe. Hargadon and Sutton (1997) and Hargadon (2003a) describe how innovation-consulting firms such as IDEO and Edison's Menlo Park lab were able to create many high impact technologies because their knowledge and expertise span many otherwise disconnected industries and communities. By recombining familiar technological components in a novel way, IDEO and Edison's team were able to pioneer technological breakthroughs in a faster and more predictable way by relying on their experience from prior R\&D. While innovation consulting firms are a particular case, other companies can also pursue a technology brokering strategy by exploiting their own unique capabilities and contexts. For instance, Cattani (2005) illustrates how Corning was able to recombine its skills and knowledge from prior R\&D in specialty glass to create the first commercially viable low-loss optical fiber in 1970.

In this paper, we study if breakthroughs originating from brokering disconnected subfields are most likely created by companies with most relevant skills and technology from prior related R\&D and capable of recombining these resources and capabilities in a novel way. First, we find empirical support in line with Fleming (2001) and Hargadon (2003a) in the sense that patents recombining two technology subfields for the first time in history are much more likely to become breakthroughs as measured by forward citations. Second, we find support for the evolutionary perspective that industrial R\&D tends to be path or history dependent (Nelson and Winter, 1982b; Helfat, 1994; Stuart and Podolny, 1996). Firms with a track record of R\&D develop new technologies in fields of established competence rather than in unfamiliar and emerging technology fields. For example, we find 84\% of all US patents granted between 1980 and 2001 to US Compustat firms, i.e. a sample of large public companies, cover at least one 
technology subfield the company has patented in before. ${ }^{2}$ Because of this path dependency, creating breakthroughs by recombining established capabilities is probably easier and more likely to succeed than by developing new capabilities from scratch. Finally, we analyze how prior related $R \& D$ experience constrains as well as supports the creation of successful new recombinations. Using patent stocks to measure companies' knowledge and capabilities in each technology subfield at a particular moment in time, we find patents recombining technology subfields for the first time in history are most likely pioneered by new companies. Nevertheless, technological breakthroughs originating from brokering disconnected subfields are most likely pioneered by companies with most prior knowledge, skills and technology and capable of recombining them in a novel way.

In contrast to prior literature on breakthroughs which frequently treated organizational capabilities as black boxes (Lavie, 2006), we use patent stocks to measure a company's capabilities in a particular technology subfield at a particular moment in time (e.g. Henderson and Cockburn, 1994; Cattani, 2005). Given that we conduct our study at the patent level of analysis, we are able to control for heterogeneity in knowledge and capabilities across companies, across R\&D projects within the same company and across time. Hence, in line with suggestions from Gatignon et al. (2002), we account for the idiosyncratic portfolio of capabilities of each company individually rather than at the industry level.

\section{Theory and Hypotheses}

\subsection{Technological Breakthroughs From Brokering Disconnected but Familiar Technological Components}

Technological progress is an evolutionary and recombinant process (Schumpeter, 1934). Grounded in detailed historical analyses of the evolution of technology, Usher (1954) and Basalla (1988) argue that technological novelty is primarily driven by the recombination of existing pieces and as such technical progress is an evolutionary rather than a revolutionary process. Usher (1929, p.11) defines technological invention as "the constructive assimilation of

\footnotetext{
${ }^{2}$ This share is particularly large given the very detailed classification of patents into currently more than 140,000 technology subclasses.
} 
pre-existing elements into new synthesis", and Nelson and Winter (1982b, p.130) argue that any sort of novelty consists to a substantial extent of a recombination of conceptual and physical materials that were previously in existence. Also technological breakthroughs, frequently labeled as revolutionary, disruptive or discontinuous with respect to prior art, have a pre-history of incremental technical developments (Fleming, 2002; Adner and Levinthal, 2002; Hargadon, 2003a). Basalla (1988) points out breakthroughs generally come from very evolutionary origins. For example, the transistor, often labeled as a disruptive or radical invention replacing vacuum tubes, has its roots in crystal radio sets which preceded vacuum tubes. Utterback (1996, p. xxvii) argues "radical innovations often are seen to be based on the synthesis of well-known technical information or components" and Usher (1954), Basalla (1988) and Hargadon (2003a) describe how major technological shifts frequently emerge from the fertilization between different preexisting but disconnected technology subfields or components.

Following this line of thought, Fleming (2001) conceptualized and operationalized invention as a recombinant search process across the technology landscape. By experimenting with the recombination of different technology components or subfields, inventors search for those recombinations with the highest fitness value (Fleming and Sorenson, 2001). Using patent data, Fleming (2001) empirically shows breakthroughs, i.e. patents with the highest variability in forward citations, most likely originate from the recombination of most familiar technology subfields, i.e. subfields with most and most recent prior patents. Nevertheless, patents re-using the same combination of subfields as prior patents are found less likely to be breakthroughs. The more a particular combination of subclasses has been used by prior patents, the less likely the patent will have a major impact (Fleming, 2001). As such, these findings suggest breakthroughs most likely materialize from recombining disconnected technology subfields or components each having a separate but productive history of technical progress in many different applications. For example, the steam engine had a very long and productive history in different applications such as water pumps before it eventually would change transportation worldwide through its application in trains and ships. Hargadon (2003a) provides many other examples of how recombining existing but disconnected technology components can foster breakthroughs. This perspective is also in line with Levinthal (1998) and Adner and Levinthal (2002) who argue that the discontinuity associated with a breakthrough does not lie in a disruptive change in technology itself. Applying the theory of punctuated equilibrium from evolutionary biology to the process of 
technical change, Adner and Levinthal (2002) argue the cause of radical technical change is a speciation event, the shift of an existing technical lineage to a new application domain causing the technology to progress in new directions. Hence, companies which are able to recombine familiar technology components in a novel way can increase their chances at a breakthroughs.

\subsection{Path Dependency, Learning and Competency Traps}

In the evolutionary theory of the firm, $R \& D$ is considered a key determinant of the company's ability to evolve with its environment and to grow in the long term (Nelson and Winter, 1982b). Yet, a company's ability to develop technologies and products to meet changing environmental demands is strongly conditioned by the company's stock of knowledge, expertise and technology from prior R\&D. The literature on organizational learning discusses at length how companies learn in a routine-based, target-oriented and path-dependent fashion (Cyert and March, 1963; Levitt and March, 1988; Nelson and Winter, 1982b). Organizations learn by encoding interpretations from experience in the past into routines that guide future behavior, including organizational search and development of new technology. The company's current stock of embedded routines and capabilities causes the company to localize its search for new technological solutions to familiar technology subfields (Stuart and Podolny, 1996). Companies develop new technologies in areas of established competence rather than in unfamiliar or emerging technology fields (Nelson and Winter, 1982b; Helfat, 1994; Sorenson and Stuart, 2000). The fact that prior R\&D is guiding future behavior, including organizational search and experimentation with new recombinations, makes industrial R\&D path or history-dependent rather than driven by the anticipation of the future.

Levitt and March (1988) and Levinthal and March (1993) point out path dependency of R\&D might lead to learning traps or competency traps, occurring in case a targeted performance with an inferior technological lineage is causing companies to reinforce established routines and capabilities without exploring alternative technologies, eventually causing established companies to be locked out in case the technology frontier shifts to unfamiliar subfields. The conformity to the company's core capabilities and technology will persist while they may not be effective anymore in solving the technological problems posed by a changing environment and as such core capabilities might become core rigidities in the face of technical change (Leonard-Barton, 1992). Ahuja and Lampert (2001) identify in more detail three learning pathologies inhibiting 
established firms from inventing breakthroughs: the familiarity trap, favoring familiar technology subfields over unfamiliar subfields; the maturity trap, favoring mature technical prior art over novel or emerging prior art; and the propinquity trap, favoring the search of solutions near existing solutions. Large established companies are most vulnerable for competency traps as they tend to specialize in the exploitation of traditional technologies driving out exploration of unproven new recombinations involving more unpredictable long-term pay offs (Levinthal and March, 1981; March, 1991). This is particularly the case because no one in the history of the company and the larger community has recognized any connection between the disconnected but familiar technological components or subfields yet (Hargadon, 2003b). Furthermore, entrants might have greater strategic incentives to invest in radically new technologies compared to incumbents (Henderson, 1993). By consequence, the invention of technologies by recombining disconnected technological components is driven by the direction and intensity of organizational search and hence by a company's stock of knowledge, skills and technology from prior related R\&D. Therefore, we hypothesize:

H1: Technology leaders, i.e. companies with most knowledge, skills and technology from prior R\&D in particular technology subfield(s), are least likely to invent technologies combining this/these technology component(s)/subfields(s) for the first time in history

\subsection{Recombinant Exploration and the Discovery of Breakthroughs}

Because path dependency of corporate R\&D hampers successful investment in unfamiliar and emerging technologies, the dominant view in the economics and management literature is that established firms are less likely to create breakthroughs compared to entrants (e.g. Cooper and Schendel, 1976; Foster, 1986). The tendency of firms with a track record of R\&D to stay close to technology fields of established competence is only harmful insofar breakthroughs are competence-destroying, i.e. in case existing capabilities and technology are rendered obsolete. Incumbent firms can only hope to pioneer such breakthroughs by going beyond familiar areas of innovation which is difficult because of inertial impediments (Tushman and Anderson, 1986; Lavie, 2006). Technological capabilities are mainly tacit in nature and accumulate in a path dependent fashion making it difficult to replace or acquire them when needed (Helfat, 1994; Garud and Nayar, 1994). Nevertheless, prior R\&D experience is likely to be supportive for the creation of competence-enhancing breakthroughs which build on and reinforce existing 
knowledge and capabilities. By engaging in R\&D, firms accumulate tacit knowledge and skills, and develop absorptive capacity, which might become important for the identification and development of pioneering technology in the future (Garud and Nayyar, 1994; Cohen and Levinthal, 1994). The question remains how a company can explore future breakthroughs while leveraging its resources and capabilities developed from prior R\&D.

So far, the literature has focused on exploration strategies established firms can adopt to counteract the liabilities of learning and competency traps. For instance, Ahuja and Lampert (2001) argue and empirically show large established firms in the chemicals industry should spent R\&D in technological fields in which the company has no prior experience, on pioneering technologies lacking any technological antecedents and build on more recently developed technical prior art, in order to invent more highly cited patents. For a sample of 128 publically traded biotech firms, Kotha et al. (2011) find both young and old firms increase the number of patents and the average number of forward citations to those patents by branching into unfamiliar technology fields, but branching has a stronger positive impact on patent value for young firms. Rosenkopf and Nerkar (2001) find large companies in the optical disk industry which go beyond local search by sourcing from technological antecedents developed outside the firm and from unfamiliar technological fields have a higher technological performance on average as measured by forward citations to patents. Nonetheless, it remains unclear if and how knowledge, capabilities and technology from prior $R \& D$ might be supporting rather than constraining the creation of breakthroughs (Lane et al, 2006). How does the new technology in unfamiliar fields relate to the company's existing capabilities and technologies?

While we recognize the importance of exploring unfamiliar and emerging technology fields, we start from the observation that organizational learning and innovation is field-specific and cumulative (Levitt and March, 1988) and as such closely related to existing organizational knowledge and capabilities. The further a company moves away from its existing knowledge and technology base, the less likely it will succeed in successfully innovating. Kogut and Zander (1992) point out that "the considerable attention given to how organizations learn has obscured the implication that organizations know something", while the learning performance is greatest when "the object of learning is related to what is already known" (Cohen and Levinthal, 1990). Furthermore, the ability to exploit external knowledge and technologies might not be sufficient 
to maintain a sustainable competitive advantage because they are also accessible for other firms in contrast to internal knowledge and technologies which are to a large extent tacit and embedded in the organization (Garud and Nayyar, 1994). For instance, Pavitt (1984) found 59\% of 3,013 most significant innovations between 1945 and 1979 as identified by industry experts in the UK were mainly based on knowledge and technology from inside the same firm, while 34\% were mainly based on external knowledge from other firms and 7\% on external knowledge from the public sector. Using survey data of R\&D directors, Gatignon et al. (2002) find that most successful innovations are those that build on both existing firm capabilities as well as on the acquisition of new capabilities.

To link knowledge and capabilities from prior R\&D to learning new knowledge for the benefit of industrial innovation, Cohen and Levinthal $(1989,1990,1994)$ developed in a series of papers the notion of absorptive capacity. Absorptive capacity is a set of abilities to evaluate the technological and commercial potential of new knowledge in a particular field, assimilate it, and apply it to commercial ends through innovation. Companies mainly obtain field-specific absorptive capacity by investing in internal R\&D. Effectively identifying, integrating and exploiting new knowledge requires research staff both competent in their field and familiar with the company's idiosyncratic needs and capabilities (Cohen and Levinthal, 1994). Nelson and Winter (1982b) argue a lot of this firm-specific knowledge is tacit in nature and therefore can only be developed through in-house R\&D experience. Furthermore, knowledge about emerging technological developments is mainly tacit in nature (Bessen, 2010) making a research staff with prior R\&D experience in the field a necessity. Besides the development of new technology, R\&D stimulates field-specific expertise, experience of past attempts and solutions, knowledge about the state of the art in the field and future business opportunities (Dosi, 1982; Cohen and Levinthal, 1989; Teece et al., 1997). As such, prior R\&D enables a company to more accurately predict the nature and direction of future technological trajectories and to exploit these opportunities through innovation (Cohen and Levinthal, 1994).

Schumpeterian innovation relies on the ability of the firm to create new combinations of existing firm resources and capabilities (Galunic and Rodan, 1998). Other discuss how companies learn new skills and innovate by recombining existing knowledge and technology with new knowledge, a notion which has been labeled as combinative capabilities by Kogut and Zander 
(1992). Existing knowledge and skills should be used as platforms for future innovation as to deter imitation and entry from competitors (Kogut and Zander, 1992). Moreover, firms can stimulate corporate entrepreneurship by building transformative capacity, i.e. the ability to maintain internally developed technology over time and to recombine the old technology to create new business opportunities (Garud and Nayyar, 1994). Not all technology from internal R\&D can be used immediately in new products or processes, but nevertheless might prove very useful in future applications. Therefore, an important challenge for established firms is to create breakthrough inventions while leveraging past competences and familiar technologies.

Inducting theory from a case study on the creation of the thermal ink-jet printer, Fleming (2002) points out that "rather than worrying about externally caused technological obsolescence, firms might stay inventive by focusing on increasing the recombinant mixing and turbulence amongst their current set of inventors and technologies". One of the main reasons why HP was able to pioneer the ink-jet printer is because it had a deep understanding of the different technology components or subfields of the printer from prior internal $\mathrm{R} \& \mathrm{D}$, and was capable of recombining these familiar components in an novel way (Fleming, 2002). Others argue that established firms should move into unfamiliar technology fields to create breakthroughs because it allows the firm to acquire new technology components that can be recombined with the company's more familiar components in order to yield more valuable technologies (e.g. Ahuja and Lampert, 2001; Kotha et al, 2011). By doing so, the existing technical lineage might shifts to a new domain of application and initiate a radical technological change (Adner and Levinthal, 2002). For instance, Corning spent millions on $R \& D$ in specialty glass without directly resulting in new products or processes. Still, the resulting technology and expertise proved very valuable when the new opportunities of fiber optics and flat-panel displays emerged (Guard and Nayyar, 1994; Cattani, 2005). Brokering the very familiar subfield of specialty glass with the disconnected and less familiar subfields of micro-electronics allowed Corning to create the first commercially viable low-loss optical fiber in 1970 and to commercially outperform its competitors to date. Another example is the invention of the Reebok pump shoe which became a huge technological and commercial success. Reebok recombined its technological expertise in shoes with the unfamiliar pump and inflation technology by collaborating with consultants from Design Continuum who had prior R\&D experience with inflation technology for medical equipment (Hargadon, 2003a). These examples illustrate that the key to creating breakthroughs not necessarily lies beyond 
company's existing areas of competence rather in brokering technology subfields of established competitive advantage with less or unfamiliar subfields.

In the remainder of the paper, we analyze whether established firms, i.e. firms with most knowledge, skills and technology from prior R\&D in a particular area of the technology landscape compared to all other companies currently active in this area, can leverage these capabilities for the creation of breakthroughs. We argue that by brokering very familiar technology subfields or components with disconnected subfields for the first time in history, established company can break free from the liabilities of learning and competency traps in order to invent breakthroughs while redeploying its competitive strengths from prior R\&D. Hence we hypothesize these companies are more likely to develop breakthroughs compared to both entrants lacking prior $\mathrm{R} \& \mathrm{D}$ experience in this area as well as equally experienced companies which do not engage in recombinant exploration:

H2: Technology leaders, i.e. companies with most knowledge, skills and technology from prior R\&D in particular technology subfield(s), are most likely to invent technological breakthroughs by recombining this/these technology component(s)/subfields(s) for the first time in history

\section{Methodology}

\subsection{Data and Sample Selection}

In line with prior research studying the emergence of technology breakthrough, we use USPTO patent data. While not all technological inventions are patented, patent data still include a large share of both failed and very successful technological discoveries, making the data appropriate to study technological breakthroughs (e.g. Fleming, 2001; Ahuja and Lampert, 2001). Furthermore, patent data provide a detailed window on when and what kind of technological knowledge, capabilities and technology are created by firms (e.g. Henderson and Cockburn, 1994; Cattani, 2005). The systematic classification of patents into very detailed technological subclasses (currently more than 140,000) enables us to identify the different subfields or components of the patented technology (Fleming, 2001), and to identify the breadth and depth of a company's R\&D activities at a very fine grained level. In case new technology classes are added or existing classes altered, all patents are retrospectively reclassified allowing us to consistently identify and 
compare a company's patent portfolio over time. We use all utility patents granted to companies by the USPTO available from the NBER and Harvard patent databases for calculating both dependent and independent variables. The NBER database includes cleaned assignee names to whom the patent is assigned, allowing us to identify each company's patent portfolio at a particular moment in time (Hall et al., 2001; Bessen, 2009). The Harvard database includes disambiguated inventor names (Lai et al., 2011). In the empirical analysis, we exclude patents with application dates before 1980 and after 2001 and patents with more than one assignee. For the calculation of dependent and independent variables, we use all patents, e.g. also patents filed before 1980 and after 2001. The final dataset consists of 1,744,625 patents and 152,928 unique companies. Because companies can patent under a variety of names, e.g. under a subsidiary's name, and because firm ownership and hence patent ownership might change over time, e.g. because of mergers and acquisitions, one might worry that using all company assigned patents will bias the results. For US Compustat firms, Hall et al. (2001) and Bessen (2009) did a major effort to match all patents to this sample of large public companies. To test the robustness of our findings, we recalculate all company variables and redo the whole empirical exercise for this sample of US Compustat firms whereby we dynamically assign patents to corporate entities to control for changes in ownership ${ }^{3}$. The Compustat sample consists of 754,611 patents assigned to 5,421 companies.

\subsection{Variables}

Dependent Variable: Technological Breakthroughs By Successfully Brokering Disconnected Technological Subfields

To identify patents recombining at least two disconnected technology subclasses for the first time in history, we follow the same methodology as Fleming et al. (2007) and use the 2008 US technology subclass concordance to go through all technology subclass assignments of all US granted patents in order to identify all first pairwise subclass combinations. A patent is labeled as recombining disconnected subfields in case it is the first patent in history with a particular

\footnotetext{
${ }^{3}$ By dynamically assigning patents to corporations, companies for instance can also gain expertise in a technology subfield by acquiring a company with expertise in that subfield. Only after the acquisition the acquired company's patent stock becomes part of the acquirer's patent stock.
} 
pairwise combination of technology subclasses ${ }^{4}$ (Fleming et al, 2007). Appendix 1 illustrates how the Reebok pump shoe patent (\#5113599) was the first in history to recombine shoe and pump technologies. For a new technology to become a breakthrough, it should have a disproportionate impact on future technological progress by serving as prior art for many subsequent inventions (Trajtenberg, 1990). In line with conventions in the field, we use forward citations to identify technological breakthroughs (e.g. Ahuja and Lampert, 2001; Singh and Fleming, 2010). We look at the distributions of forward citation counts of patents sharing the same 3-digit technology class and isolate outliers in the top of the distributions. See appendix 2 for a more detailed explanation.

\section{Explanatory variables}

A company is typically active in different fields of the technology landscape. The amount of companies' experience in each subfield might differ and change over time. By designing a technology roadmap and engaging in $\mathrm{R} \& \mathrm{D}$, companies develop technology and expertise in particular subfields of the landscape, necessarily restricting investments in other subfields due to scarce resources. Over time, companies can enter unfamiliar technology subfields, abandon familiar subfields, and obtain or lose technology leadership in other subfields. To account for this heterogeneity in prior knowledge, skills and technology across companies, across different R\&D projects within the same company, and over time, we calculate a measure of pre-existing capabilities and technology for each new technological invention granted by a patent.

To calculate a patent-level measure of pre-existing capabilities in the same subfield(s) as the focal patent, we identify for each patent whether the assigned company has prior patents in the same subfield(s) as the focal patent. We calculate a dummy of prior experience (PE) to indicate whether the company has prior patent(s) in at least one of the technology subfields of the focal patent as well as a the number of the patent's technology subclasses in which the company has patented before (CFPE). For those patents recombining disconnected technology subclasses, we identify whether the company has prior patents in at least one of the previously disconnected

\footnotetext{
${ }^{4}$ We look at the first combination of two technology subclasses at the patent level in history. The order in which the subclasses appear on the patent document is irrelevant, so the combination of subclass A and subclass B is treated the same as the combination of subclass B and subclass A. For a patent with $n$ subclasses, the number of unique pairwise combinations is $\frac{n !}{2 \times(n-2) !}$. For instance, a patent with 3 subclasses $\mathrm{A}, \mathrm{B}$ and $\mathrm{C}$ has three combinations: $\mathrm{AB}$, AC, BC. For a more detailed explanation of this measure, see Fleming et al. (2007).
} 
technology subfields (PE DF) as well as a count of previously disconnected subclasses of prior experience (CFPE DF), and/or whether the assigned company has prior patent(s) in the subfields of the focal patent which are not combined for the first time (PE NDF) as well as a count of nondisconnected subfields of prior experience (CFPE NDF). In addition, we calculate a dummy for incumbency or technology leadership (TL) being 1 for patents assigned to companies which are above the $95^{\text {th }}$ percentile of patent ownership in the same subclass(es) as the focal patent among all assignees filing at least 1 patent in the same subclass and application year. By doing so, we only take into account companies which are currently still active in a particular technology subfield. We make a distinction between technology leadership in 1 subfield of the focal patent (CFTL 1) and technology leadership in at least 2 subfields of the focal patent (CFTL >1). Again, a distinction is made for patents recombining disconnected subfields between being technology leader in at least one of the previously disconnected subfields (TL DF), being technology leader in exactly 1 of the previously disconnected subfields (TL DF 1), being technology leader in more than 1 of the previously disconnected subfields (TL DF >1); and/or being technology leader in at least one of the patent's subfields which are not being recombined for the first time (TL NDF), being technology leader in exactly 1 of the non-disconnected subfields (TL NDF 1) and being technology leader in more than 1 of the non-disconnected subfields (TL NDF >1). See table 1 for a more detailed description on the calculation of the variables and figure 1 for a fictitious example for a single patent. Figure 2 illustrates the distribution of companies' patent stock for a particular technology subclass in a particular year.

\section{Table 1}

Figure 1

Figure 2

\section{Control variables}

At the patent level, we include company, team and patent characteristics as control variables. First, we control for the scale of the applicant company and the extent to which the company has a technologically diversified patent portfolio. Second, we control for team size, average team experience, average team specialization and the size of the social network of the inventors. Third, we control for the number of backward patent citations, the number of citations to non- 
patent literature, the number of main technology classes and the number of pairwise combinations of a patent's technology subclasses. Finally, we include application year dummies and 3-digit technology class dummies. We take the natural logarithm of all count variables and mean center variables used in interaction terms. Given that we want to include both small and large companies in our analysis, we are not able to collect additional data on R\&D expenditures, net income and number of employees given that such data is typically not available for smaller companies. Notice that prior research has found a strong positive correlation between a company's R\&D expenditures and the number of patents filed and granted (e.g. Pakes \& Griliches, 1980). By including the number of prior patents granted to the company, we at least partially control for past $\mathrm{R} \& \mathrm{D}$ expenditures. To control for remaining unobserved correlation across patents assigned to the same corporate entity, we use robust clustered standard errors at the company level.

\subsection{Descriptive Statistics 5}

Around half of the patents in our sample (53\%) are found to recombine at least two technology subfields for the first time in history, while $3 \%$ of all patents are breakthroughs as measured by being an outlier in the distribution of forward citations. Of the patents making a new recombination, $3.7 \%$ are found to be breakthroughs compared to $2.3 \%$ for the patents without a new combination, i.e. a percentage difference of $63 \%$. Adopting a more restrictive definition of breakthrough by looking at for instance 3, 4 or 10 standard deviation outliers in terms of forward citations makes the share of breakthrough patents with new recombinations even larger, respectively $75 \%, 85 \%$ and $163 \%$ larger. As such, companies exploring new recombinations of technology subfields or components can significantly increases their chances at a breakthrough. In the remainder of the analysis, we restrict attention to this particular type of breakthroughs originating from the recombination of disconnected subfields.

Table 2

In line with the evolutionary perspective that the direction of new $R \& D$ projects is constrained by prior R\&D (Helfat, 1994; Stuart and Podolny, 1996), we find 68\% of all patents are assigned to companies with prior patents in the same subclass(es) as the focal patent while $23 \%$ of all

${ }^{5}$ all T-tests on statistical significance of mean differences have $\operatorname{Pr}(|\mathrm{T}|>|\mathrm{t}|)=0.0000$ ) 
patents are assigned to companies with prior patents but not in the same subfields and $9 \%$ to companies without prior patents. As expected, the large majority of all technology development is done by companies with prior $\mathrm{R} \& \mathrm{D}$ and targeted at familiar technology subfields. This path dependency of R\&D becomes even more apparent when looking at US Compustat firms, i.e. a sample of large public companies. $84 \%$ of their patents are assigned to companies with prior patents in the same subclass(es) as the focal patent. A strong positive correlation between company scale, i.e. the number of prior patents, and prior experience (PE) (0.56) and between company scale and count subfields of prior experience (CFPE) (0.58) in table 3 illustrates companies with more prior R\&D typically invent new technologies in areas of established competence rather than to move into unfamiliar or emerging technology subfields.

Figure 3

Table 3

The descriptive statistics in figure 3 also support the hypothesis that companies with more prior knowledge, skills and technology in the respective subfields tend to focus relatively more on exploiting existing combinations rather than exploring novel recombinations. $56.3 \%$ of patents assigned to companies entering the field have a new recombination, compared to $51.9 \%$ and $48.8 \%$ for companies with prior experience and technology leaders respectively. While brokering increases the likelihood of creating breakthroughs, companies familiar with the technology subfields and particularly technology leaders seem less likely to do so.

\section{Figure 3}

\section{Figure 4}

Nevertheless, conditional on recombining disconnected subfields, patents of companies with prior R\&D in the subfield(s) and predominantly patents of technology leaders are more likely to be breakthroughs. As illustrated in figure 3,5\% of patents with new combinations assigned to technology leaders are breakthroughs compared to $3.9 \%$ and $3.2 \%$ for patents assigned to companies with prior experience and to companies without prior experience respectively; making patents of technology leaders $28 \%$ more likely to be breakthroughs compared to patents of companies with prior experience, and patents of companies with prior experience $17 \%$ more 
likely compared patents of companies entering the field ${ }^{6}$. Figure 4 illustrates technology leadership and prior experience in (a) previously disconnected subfield(s) significantly increases the likelihood of successfully brokering compared to technology leadership and prior experience in (a) non-disconnected subfield(s). In conclusion, companies with most prior experience seem to have less incentives and/or ability to explore new recombinations of familiar components or subfields. Nonetheless, established firms capable of leveraging knowledge, skills and technology accumulated from prior R\&D by recombining familiar technology in a new way are most likely to create breakthroughs. Companies without or with less $\mathrm{R} \& \mathrm{D}$ experience seem to direct their efforts towards exploring new recombinations but these attempts are more likely to fail.

\subsection{Multivariate Analysis}

Different companies might have different incentives and abilities to broker technology subfields. Conditional on this propensity of brokering, their attempts might be more or less likely to result in a breakthrough. To control for this selection, we estimate a Probit model with sample selection using the heckprob command in Stata. The selection equation estimates the likelihood a patent recombines at least two disconnected technology subclasses for the first time in history, and the second stage estimates the likelihood of becoming a technological breakthrough conditional on having a new recombination. The results from the regression analysis are presented in table 4 for the full sample and in table 5 for the Compustat sample.

\section{Table 4}

We will first discuss the results of the selection equation estimating the probability of recombining disconnected technology subfields before discussing the second stage estimating the likelihood for a breakthrough. Results from table 4 show patents assigned to companies with prior experience in the same subfield(s) as the focal patent are $23 \%$ less likely to bridge disconnected subfields compared to patents assigned to companies entering the field. Count subfields of prior experience has a negative and decreasing effect. The more subclasses of a patent the assigned company has prior experience with, the less likely the patent will make a new

\footnotetext{
${ }^{6}$ Notice that while we focus on a particular type of breakthroughs stemming from the recombination of disconnected technology subfields, patents without a new combination assigned to companies with more prior patents in the subfields are also more likely to have a high impact compared to patents without a new combination assigned to companies with less experience. This is probably less surprising as it involves less novel or radical inventions for which established firms have a competitive advantage compared to entrants.
} 
recombination. Technology leaders tend to focus most on refining familiar combinations making their patents $49 \%$ less likely to bridge disconnected subclasses compared to entrants and $26 \%$ less likely compared to non-leading companies previously active in the subfield(s). In case a company is technology leader in just one of the patent's subfields, this likelihood decreases with $1.3 \%$ while patents of companies being technology leader in more than 1 subfield are $18 \%$ less likely. These findings support hypotheses H1. Companies with most knowledge, skills and technology from prior $R \& D$ in particular technology subfield(s), are least likely to invent technologies recombining this/these technology component(s)/subfields(s) for the first time in history. In addition, patents of larger companies are more likely to make new combinations as are patents developed by smaller teams, teams with inexperienced or specialized inventors and teams with a broad external social network. Result for the control sample of Compustat firms in table 5 are very similar in sign and magnitude.

\section{Table 5}

Conditional on brokering subfields, patents assigned to companies with prior experience are found $21 \%$ more likely to become a breakthrough compared to patents assigned to companies new to the field. Prior experience in a previously disconnected subfield increases the likelihood with $27 \%$ while prior experience in a non-disconnected subfield results in an increase of $11 \%$. The more subfields the assigned company is familiar with, the larger the likelihood it will successfully recombine them. A broad experience with different technology components from prior R\&D stimulates exploration learning and the ability to successfully broker. Particularly the number of previously disconnected subfields of prior experience has a positive and nondecreasing impact. The number of non-disconnected subfields in which the company has prior experiences has an inverted $\mathrm{u}$-shape relationship with being a breakthrough.

Patents assigned to technology leaders are $45 \%$ more likely to be a breakthrough compared to patents of companies new to the field. Technology leaders outperform non-leaders with prior experience as their patents are $24 \%$ more likely to be a breakthrough. In case a company is technology leader in just one of the patent's subfields, the likelihood at a breakthrough increases with $16 \%$ compared to patents of companies with prior experience but not technology leading. Technology leadership in more than 1 subclass of the focal patent is not significant. Technology leadership in a previously disconnected subclass results in an increase of $17 \%$ compared to 
patents of non-leading companies with prior experience in a disconnected subfield. We dont find a significant effect for patents of technology leaders in one of the non-disconnected subfields (Table 4 column 7). Again making a distinction between technology leadership in 1 or multiple subfields and whether the leadership is a disconnected or in a non-disconnected subfield, we find technology leadership in 1 disconnected subfield results in an increase of $10 \%$ compared to prior experience in disconnected subfield, technology leadership in 1 non-disconnected subfield results in an increase of $14 \%$ compared to prior experience in a non-disconnected subfield, while technology leadership in multiple disconnected or multiple non-disconnected subfield is not significant. Together these results support hypothesis $\mathrm{H} 2$ and the idea that established firms which leverage knowledge, skills and technology accumulated from prior R\&D by brokering technology subfields of established competence with less or unfamiliar subfields are most likely to create breakthroughs. They outperform companies unfamiliar with the technology components and companies equally familiar with the components but which are not capable of recombining them in a novel way. Finally, patents of larger companies are less likely to successfully recombine disconnected subfields while patents developed by larger teams, more experienced inventors and inventors with a broader social network are more likely. The estimated effects for the control sample of Compustat firms in table 5 are very similar in terms of direction and size except for the fact that CFTL DF 1 is not significant anymore in the final regression (table 5 column 7), while TL DF remains significant (table 5 column 3).

Because observational patent data has no random treatment assignment of companies with and without prior technological knowledge and capabilities, we apply propensity score matching to improve the causal inference of our estimations. Given that companies with prior experience and particularly technology leaders tend to be larger, more diversified and tend to employ more experienced inventors with a broader social network, as shown in table 3, we need to control for these confounding effects. Are technology leaders more likely to invent breakthrough because they recombine knowledge, expertise and technology from prior related R\&D or is it because they have slack resources, are more diversified and employ different kind of R\&D teams? By matching on company, inventor and patent characteristics, we control for the mediation of the pretreatment control variables by creating a better balance between the treatment and control patents hereby leading to less model dependence and reducing statistical bias in estimating the impact of prior domain-specific knowledge and technology. To do so, we apply propensity score 
matching within groups of patents sharing the same 3-digit technology class and application year. Hence, we extend the standard matching procedure pioneered by Jaffe et al. (1993) by matching on additional company, inventor and patent characteristics. The propensity score matching procedure is explained in more detailed in appendix 3. Results from the matching are presented as the average treatment effect on the treated and can be found in table 6 . The findings are in line with the results from the regression analysis on the full sample.

\section{Table 6}

In conclusion, the results show how knowledge, skills and technology from prior R\&D both constrain and support the development of breakthroughs from new recombinations of familiar subfields. Firms with most prior related R\&D tend to focus most on refining familiar combinations rather than exploring unfamiliar technology subfields or new recombination using familiar subfields. At the same time, we find companies with most knowledge and skills from prior R\&D and capable of leveraging these capabilities by brokering subfields of established competence with less or unfamiliar subfields most likely to create breakthroughs.

\section{Discussion and Conclusion}

The main objective of this paper is to study if and how established firms can create technological breakthroughs by leveraging their knowledge, skills and technology accumulated from prior R\&D rather than by developing new resources and capabilities from scratch. We study one particular exploration strategy identified in the literature as key for fostering the creation of breakthroughs, namely creating inventions from new recombinations of familiar technological components or subfields (Fleming, 2001; Hargadon, 2003a).

Adopting an evolutionary perspective of corporate R\&D, we argue and show that capabilities from prior related $R \& D$ both constrain and support the development of breakthroughs. Companies with most knowledge and skills from prior related R\&D, as measured by the company's patent stock in the same technology subfields, are least likely to develop new recombinations of familiar technological subfields. As such, we find that companies with a track record of related $\mathrm{R} \& \mathrm{D}$ typically struggle to explore novel recombinations of familiar technologies and to move into new markets (Hargadon, 2003b). Nevertheless, established firms 
capable of leveraging skills and technology accumulated from prior R\&D by recombining technology subfields of established competence with less or unfamiliar subfields are most likely to create breakthroughs. Therefore, firms need to recognize how they can create business opportunities in new and uncertain markets around innovative combinations of familiar technology components. By recombining internal knowledge and capabilities firms can create breakthroughs and increase the returns from prior investments in $R \& D$. Because industrial $R \& D$ is path dependent, creating breakthroughs by recombining established technological capabilities is probably more successful than by creating new capabilities from scratch. Our findings suggest that the literature on technological change and organizational innovation seems too much focused on a less common type of breakthroughs rendering established knwoledge and capabilities obsolete.

We believe our paper contributes to the strategic management literature by studying the origins of competitive advantage. The resource based view of the firm argues a company's competitive advantage relies on the application of firm specific resources and capabilities, such as knowledge, skills and technology accumulated from R\&D inside the firm. These resources are mainly tacit in nature and develop in a path dependent fashion making it difficult to replace or acquire them when needed (Helfat, 1994; Garud and Nayar, 1994). Studying how technological incumbents can make better use of these resources is important given that established firms are responsible for the large majority of all $R \& D$ investments worldwide and because competenceenhancing technological breakthroughs, which build on prior knowledge and capabilities, are more common than competence-destroying breakthroughs. In line with theory on dynamic capabilities (Teece et al., 1997), we study the evolutionary process of how companies develop a competitive advantage by accumulating knowledge, skills and technology from R\&D, and how companies can exploit this advantage by creating innovative combinations of familiar technology components.

Our paper has some obvious limitations. First, we limit ourselves to the creation of technological breakthroughs while the initial creation of the invention and its commercialization are two different things. Many companies creating technological breakthroughs fail to turn them into a commercial success. A classic example is the failure of Xerox to commercialize some of the most important breakthroughs in personal computing including the graphical user interface and 
the mouse. Linking data on technological breakthroughs with data on the commercialization of the products or services incorporating the technological breakthroughs provides an interesting avenue for future research. For instance, which company is most likely to turn a technological breakthroughs into a commercial breakthough and under which conditions? Second, we identify technological leaders or incumbents by looking at the distribution of companies' patent stocks in technology subfields. Yet, technology leaders and market incumbents are not necessarily the same companies. There is not a one-to-one relationship between technology, products and services, and markets. Prior research shows that the fear for cannibalizing current sales of existing products strongly reduces the incentives of market incumbents to pioneer radical innovations (Henderson, 1993). In this paper, we are unable to control for differences in incentives due to market incumbency. Finally, a set of more common limitations are related to the use of patent data. While frequently used as a measure of firm knowledge and innovation, patent data do not capture all knowledge, experience and technology from prior R\&D. Not all inventions are patented, and failed $\mathrm{R} \& \mathrm{D}$ experiments might not lead to patents while nevertheless resulting in more knowledge and skills inside the firm.

Future research could study in more detail how established firms can increase their recombinant exploration capacity. Companies can potentially reconcile the tension between path dependent R\&D and exploration by for instance hiring researchers with skills and experience complementary to its own $\mathrm{R} \& \mathrm{D}$ personnel or by mixing $\mathrm{R} \& \mathrm{D}$ teams with researchers working in a company's most familiar technology subfields and researchers working in emerging and/or less familiar technology fields. 


\section{References}

Adner, R., D. Levinthal (2002). The Emergence of Emerging Technologies. California Management Review. 45 50-66.

Ahuja, G., C.M. Lampert (2001). Entrepreneurship in the Large Corporation: A Longitudinal Study of how Established Firms Create Breakthrough Inventions. Strategic Management Journal. 22 521-543.

Basalla G. (1988). The Evolution of Technology. Cambridge University Press, Cambridge, MA.

Bessen J. (2009). Matching Patent Data to Compustat. NBER PDP Project.

Bessen J. (2010). Communicating Technical Knowledge. Boston University School of Law Working Paper no. 10-35.

Cattani G. (2005). Preadaptation, Firm Heterogeneity, and Technological Performance: A Study on the Evolution of Fiber Optics, 1970-1995. Organization Science. 16(6) 563-580.

Cohen, W.M., D.A. Levinthal. (1989). Innovation and learning: the two faces of R\&D. The Economic Journal. 99(397) 569-596.

Cohen, W.M., D.A. Levinthal. (1990). Absorptive Capacity: A New Perspective on Learning and Innovation. Administrative Science Quarterly. 35(1) 128-152.

Cohen, W.M., D.A. Levinthal. (1994). Fortune Favors the Prepared Firm. Management Science.40(2) 227-251.

Cooper, A., D. Schendel (1976). Strategic Responses to Technological Threats. Business Horizons, February 61-69.

Cyert, R.M., J. March (1963). A Behavioral Theory of the Firm. Prentice Hall, Englewood Cliffs, NJ.

Dosi, G. (1982). Technological Paradigms and Technological Trajectories: A Suggested Interpretation of the Determinants and Directions of Technical change. Research Policy. 11 147-162.

Dosi, G. (1988). Sources, procedures, and microeconomic effects of innovation. Journal of Economic Literature. 26 1120-1171.

Fleming, L. (2001). Recombinant Uncertainty in Technological Search. Management Science. 47(1) 117-132.

Fleming, L., O. Sorenson. (2001). Technology as a Complex Adaptive System: Evidence from Patent Data. Research Policy. 30(7) 1019-1039.

Fleming, L. (2002). Finding the Organizational Sources of Technological Breakthroughs: The Story of Hewlett-Packard's Thermal Ink-Jet. Industrial and Corporate Change. 11(5) 1059-1084.

Fleming, L., S. Mingo, D. Chen (2007). Collaborative Brokerage, Generative Creativity, and Creative Success. Administrative Science Quarterly. 52(3) 443-475.

Foster R. (1986). Innovation: The Attackers Advantage. Summit Books, New York. 
Galunic, D.C., S. Rodan (1998). Resource Recombinations in the Firm: Knowledge Structures and the Potential for Schumpeterian Innovation. Strategic Management Journal. 19(12) 1193-1201.

Garud, R., P.R. Nayyar (1994). Transformative Capacity: Continual Structuring by Intertemporal Technology Transfer. Strategic Management Journal. 15(5) 365-385.

Gatignon, H., M.L. Tushman, W. Smith, P. Anderson (2002). A Structural Approach to Assessing Innovation: Construct Development of Innovation Locus, Type, and Characteristics. Management Science. 48(9) 1103-1122.

Hall, B. H., A. B. Jaffe, and M. Trajtenberg (2001). The NBER Patent Citation Data File: Lessons, Insights and Methodological Tools. NBER Working Paper 8498.

Hargadon, A., R.I. Sutton (1997). Technology Brokering and Innovation in a Product Development Firm. Administrative Science Quarterly. 42(4) 716-749.

Hargadon, A. (2003a). How Breakthroughs Happen: The Surprising Truth About How Companies Innovate. Harvard Business School Press, Boston, MA.

Hargadon, A. (2003b). Retooling R\&D: Technology brokering and the pursuit of innovation. Ivy Business Journal. November/December 1-7.

Hargadon, A. (2004). Brokers of Innovation: Lessons from the Past. Focus. 8(1) 32-35.

Helfat C.E. (1994). Evolutionary Trajectories in Petroleum Firm R\&D. Management Science. 40(12) 1720-1747.

Henderson, R. (1993). Underinvestment and Incompetence as Responses to Radical Innovation: Evidence from the Photolithographic Alignment Equipment Industry. RAND Journal of Economics, 24(2) 248-270.

Henderson, R., K. Clark (1990). Architectural Innovation: the Reconfiguration of Existing Product Technologies and Failure of Established Firms. Administrative Science Quarterly. 35 9-30.

Henderson, R., I.M. Cockburn (1994). Measuring competence? Exploring firm effects in pharmaceutical research. Strategic Management Journal. 15 63-84.

Hill, C.W.L., F.T. Rothaermel (2003). The Performance of Incumbent Firms in the Face of Radical Technological Innovation. Academy of Management Review. 28(2) 257-274.

Jaffe, A. B., M. Trajtenberg, R. Henderson. (1993). Geographic localization of knowledge spillovers as evidenced by patent citations. Quarterly Journal of Economics. 108(3) 577598.

Kogut, B., U. Zander (1992). Knowledge of the Firm, Combinative Capabilities, and the Replication of Technology. Organization Science. 3(2) 383-397.

Kotha, R., Y. Zheng, G. George (2011). Entry into New Niches: The Effects of Firm Age and the Expansion of Technological Capabilities on Innovative Output and Impact. Strategic Management Journal. 32 1011-1024.

Lai, R., A. D'Amour, A. Yu, Y. Sun, V. Torvik, L. Fleming (2011). The careers and coauthorship networks of U.S. patent-holders, since 1975. Harvard Business School working paper 
Lane, P.J., B.R. Koka, S. Pathak (2006). The Reification of Absorptive Capacity: A Critical Review and Rejuvenation of the Construct. Academy of Management Review. 31(4) 833863.

Lavie D. (2006). Capability Reconfiguration: An Analysis of Incumbent Responses to Technological Change. The Academy of Management Review. 31(1) 153-174.

Leonard-Barton D. (1992). Core Capabilities and Core Rigidities: A Paradox in Managing New Product Development. Strategic Management Journal. 13 Special Issue: Strategy Process: Managing Corporate Self-Renewal 95-112.

Levinthal, D.A., J.G. March (1993). The Myopia of Learning. Strategic Management Journal. 95-112.

Levinthal, D. (1998). The Slow Pace of Rapid Technological Change: Gradualism and Punctuation in Technological Change. Industrial and Corporate Change. 7(2) 217-247.

Levitt, B., J.G. March (1988). Organizational Learning. Annual Review of Sociology. 14 319338.

March J. (1991). Exploration and Exploitation in Organizational Learning. Organization Science. 2(1) $71-87$.

Methé, D., A. Swaminathan, W. Mitchell (1996). The Underemphasized Role of Established Firms as the Sources of Major Innovations. Industrial and Corporate Change. 5(4) 11811203.

Nelson, R., S. Winter (1982a). Toward an Evolutionary Theory of Economic Capabilities. American Economic Review. 63(2) 440-449.

Nelson, R., S. Winter (1982b). An Evolutionary Theory of Economic Change. Harvard university Press, Cambridge, MA

Pakes A., Z. Griliches (1980). Patents and R and D at the Firm Level: A First Report. Economics Letter. 5 377-381.

Prahalad, C. K. and G. Hamel. (May-June 1990). The core competence of the corporation. Harvard Business Review. 79-91.

Pavitt K. (1984). Sectoral Patterns of Technical Change: Towards a Taxonomy and a Theory. Research Policy. 13(6) 343-373.

Roberts, E. B., C. A. Berry (1984). Entering New Businesses: Selecting Strategies for Success. MIT Sloan School of Management Working Paper, nr 1492-3-84.

Rosenkopf, L., A. Nerkar (2001). Beyond Local Search: Boundary-Spanning, Exploration, and impact in the Optical Disk Industry. Strategic Management Journal. 22(4) 287-306.

Schumpeter J.A. (1934). The Theory of Economic Development. Harvard university Press, Cambridge, MA

Schumpeter J.A. (1942). Capitalism, Socialism and Democracy. Harper and Row: New York

Singh, J., L. Fleming. (2010). Lone Inventors as Sources of Breakthroughs: Myth or Reality? Management Science. 56(1) 41-56. 
Sorenson, J. , T.E. Stuart (2000). Aging, Obsolescence, and Organizational Innovation. Administrative Science Quarterly. 45 81-113.

Stuart, T.E., J.M. Podolny (1996). Local Search and the Evolution of Technological Capabilities. Strategic Management Journal. Special Issue: Evolutionary Perspectives on Strategy 17 21-38.

Tan, J., L. Jiang, M. Thursby (2011). Incumbent Firm Invention in Emerging Fields: Evidence from the Semiconductor industry. Strategic Management Journal. 32(1) 55-75.

Teece, D.J., G. Pisano, A. Shuen. (1997). Dynamic capabilities and strategic management. Strategic Management Journal. 18(7) 509-533.

Teece, D.J. (2007). Explicating Dynamic Capabilities: The Nature and Microfoundations of (Sustainable) Enterprise Performance. Strategic Management Journal. 28 1319-1350.

Trajtenberg, M. (1990). Economic Analysis of Product Innovation : The Case of CT Scanners. Harvard University Press, Cambridge, MA.

Tripsas M. (1997). Unraveling the Process of Creative Destruction: Complementary Assets and incumbent Survival in the Typsetter Industry. Strategic Management Journal. 18 119142.

Tushman, M., P. Anderson (1986). Technological Discontinuities and Organizational Environments. Administrative Science Quarterly. 31 439-465.

Usher, A.P. (1954). A History of Mechanical Invention. Cambridge, MA.

Utterback, J. (1996). Mastering the Dynamics of Innovation. Harvard Business School Press, Boston, MA. 
Figure 1: Example Calculation Independent Variables

\begin{tabular}{|c|c|c|c|}
\hline \multicolumn{4}{|c|}{$\begin{array}{l}\text { Patent: X } \\
\text { Assignee Company: Y } \\
\text { Technology subclasses patent X: A, B, C } \\
\text { Application year patent X: } 2005\end{array}$} \\
\hline Pairwise Subclass Combination & New combination? & & \\
\hline $\mathrm{AB}$ & Yes & & \\
\hline $\mathrm{AC}$ & No & & \\
\hline \multirow[t]{2}{*}{$\mathrm{BC}$} & No & & \\
\hline & $\begin{array}{l}\text { Prior granted patents } \\
\text { (Y filed before 2005)? }\end{array}$ & $\begin{array}{l}\text { Count prior granted patents } \\
\text { (Y filed before 2005)? }\end{array}$ & Y Technology Leader in 2005? \\
\hline A & Yes & 380 & Yes \\
\hline $\mathrm{B}$ & No & 0 & No \\
\hline $\mathrm{C}$ & Yes & 56 & No \\
\hline \multirow{2}{*}{\multicolumn{3}{|c|}{ Company prior experience (PE) }} & Value for Patent X \\
\hline & & & 1 \\
\hline \multicolumn{3}{|c|}{ Company prior experience in disconnected subfield(s) (PE DF) } & 1 \\
\hline \multicolumn{3}{|c|}{ Company prior experience in non-disconnected subfield(s) (PE NDF) } & 1 \\
\hline \multicolumn{3}{|l|}{ Technology leader (TL) } & 1 \\
\hline \multicolumn{3}{|c|}{ Technology leader in disconnected subfield(s) (TL DF) } & 1 \\
\hline \multicolumn{3}{|c|}{ Technology leader in non-disconnected subfield(s) (TL NDF) } & 0 \\
\hline \multicolumn{3}{|c|}{ Count subfields of prior experience (CFPE) } & $\operatorname{Ln}(2+1)$ \\
\hline \multicolumn{3}{|c|}{ Count subfields of prior experience in disconnected subfield(s) (CFPE DF) } & $\operatorname{Ln}(1+1)$ \\
\hline \multicolumn{3}{|c|}{ Count subfields of prior experience in non-disconnected subfield(s) (CFPE NDF) } & $\operatorname{Ln}(1+1)$ \\
\hline \multicolumn{3}{|c|}{ Technology leadership in 1 subfield (CFTL 1) } & 1 \\
\hline \multicolumn{3}{|c|}{ Technology leadership in more than 1 subfield (CFTL $>1)$} & 0 \\
\hline \multicolumn{3}{|c|}{ Technology leadership in 1 disconnected subfield(s) (CFTL DF 1) } & 1 \\
\hline \multicolumn{3}{|c|}{ Technology leadership in more than 1 disconnected subfield(s) (CFTL DF >1) } & 0 \\
\hline \multicolumn{3}{|c|}{ Technology leadership in 1 non-disconnected subfield(s) (CFTL NDF 1) } & 0 \\
\hline \multicolumn{3}{|c|}{ Technology leadership in more than 1 non-disconnected subfield(s) (CFTL NDF >1) } & 0 \\
\hline
\end{tabular}

Figure 2: Example Distribution of Patent Stock by Company: Class 709: Electrical Computers and Digital Processing Systems: Multicomputer Data Transferring, Subclass 203: Distributed Data Processing Client/Server, Application Year 2001, Only companies with at least 2 prior patents are shown

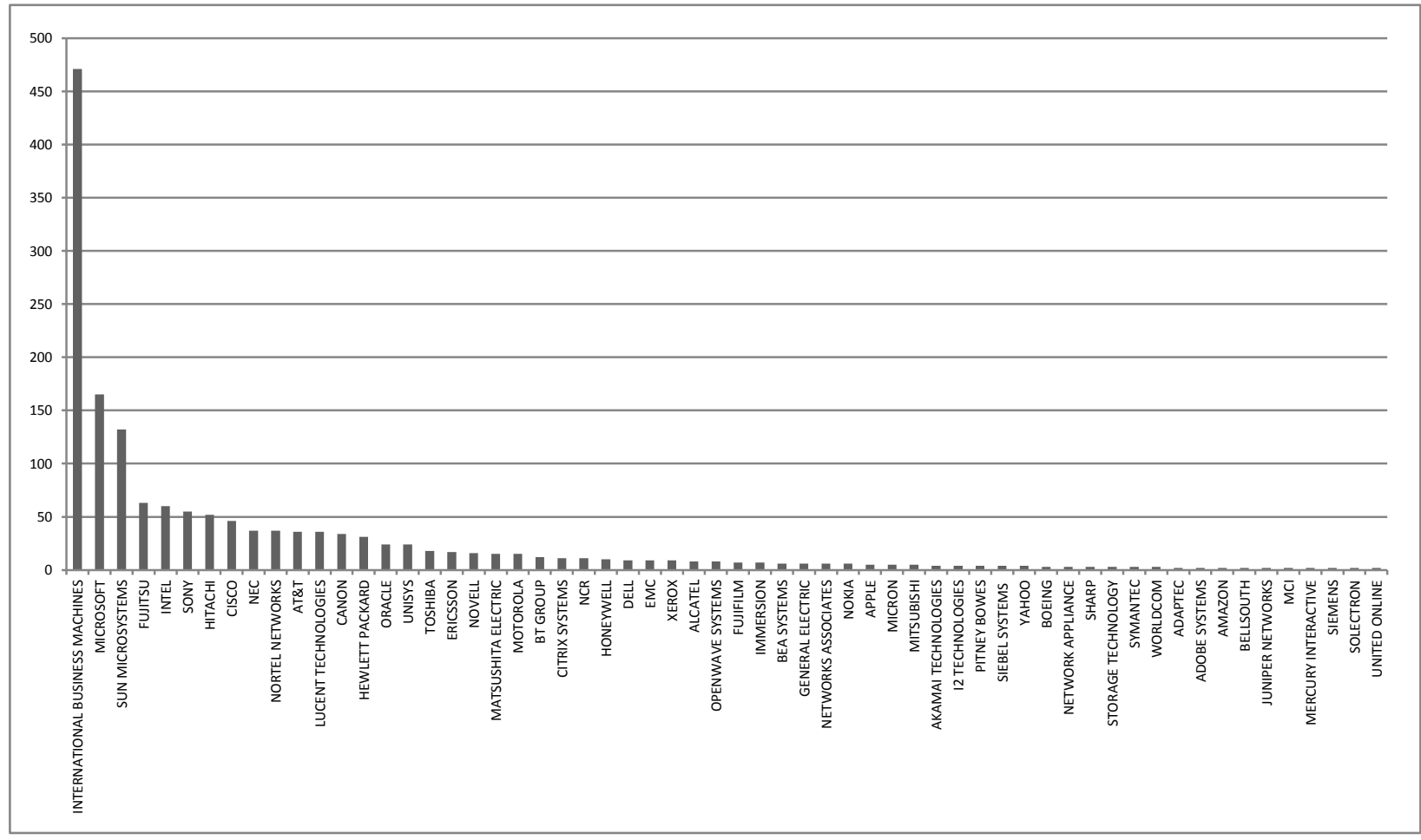


Figure 3: Distribution of All Company-Assigned U.S. Granted Patents, By Type Company, Recombining Disconnected Technology Subfields and Technological Breakthrough

\begin{tabular}{|c|c|c|}
\hline Type Assignee & $\begin{array}{c}\text { New } \\
\text { Combination? }\end{array}$ & $\begin{array}{c}\text { \% Technological } \\
\text { Breakthroughs }\end{array}$ \\
\hline $\begin{array}{c}\text { Company Technology Leader } \\
(7.1 \% \text { of patents in sample) }\end{array}$ & Yes: $48.8 \%$ & $5.0 \%$ \\
\cline { 2 - 3 } & No: $51.2 \%$ & $2.8 \%$ \\
\hline $\begin{array}{c}\text { Company Prior Patents } \\
\text { in the subfield(s) } \\
\text { No Technology Leader } \\
(61.2 \%)\end{array}$ & Yes: $51.9 \%$ & $3.9 \%$ \\
\cline { 2 - 3 } & No: $48.1 \%$ & $2.4 \%$ \\
\hline $\begin{array}{c}\text { Company No Prior Patents } \\
\text { in the subfield(s) } \\
\text { No Technology Leader } \\
(31.7 \%)\end{array}$ & Yes: $56.3 \%$ & $3.2 \%$ \\
\cline { 2 - 3 } & No: $43.7 \%$ & $1.9 \%$ \\
\hline
\end{tabular}

Figure 4: Distribution of All Company-Assigned U.S. Granted Patents Recombining Disconnected Technology Subfields, By Type Company and Technological Breakthrough

\begin{tabular}{|c|c|c|}
\hline Type Assignee & Type Experience & $\begin{array}{l}\% \text { Technological } \\
\text { Breakthroughs }\end{array}$ \\
\hline \multirow{3}{*}{$\begin{array}{l}\text { Company Technology Leader (TL) } \\
\text { (6.5\% of patents in sample) }\end{array}$} & $\begin{array}{l}\text { TL in disconnected subfield(s) (TL DF) } \\
(53.0 \%)\end{array}$ & $5.3 \%$ \\
\hline & $\begin{array}{l}\text { TL in non-disconnected subfield(s) (TL NDF) } \\
(27.6 \%)\end{array}$ & $4.7 \%$ \\
\hline & $\begin{array}{l}\text { TL in disconnected and non-disconnected subfield(s) } \\
\text { (TL DF + TL NDF) } \\
(19.3 \%)\end{array}$ & $4.3 \%$ \\
\hline \multirow{3}{*}{$\begin{array}{c}\text { Company Prior Experience } \\
\text { in the subfield(s) (PE) } \\
\text { No Technology Leader } \\
(59.8 \%)\end{array}$} & $\begin{array}{c}\text { PE in disconnected subfield(s) (PE DF) } \\
(57.2 \%)\end{array}$ & $4.0 \%$ \\
\hline & $\begin{array}{c}\text { PE in non-disconnected subfield(s) (PE NDF) } \\
(6.1 \%)\end{array}$ & $3.5 \%$ \\
\hline & $\begin{array}{l}\text { PE in disconnected and non-disconnected subfield(s) } \\
\text { (PE DF + PE NDF) } \\
(36.7 \%)\end{array}$ & $3.9 \%$ \\
\hline $\begin{array}{c}\text { Company No Prior Experience } \\
\text { in the subfield(s) } \\
\text { No Technology Leader } \\
(33.6 \%)\end{array}$ & & $3.3 \%$ \\
\hline
\end{tabular}




\section{Table 1: Description of Variables (Patent Level)}

\begin{tabular}{llc} 
Variable & Type & Measure \\
\hline
\end{tabular}

New combination

High impact new combination

Company prior experience (PE)

Company prior experience in disconnected subfield(s) (PE DF)

Company prior experience in nondisconnected subfield(s) (PE NDF)

Technology leader (TL)

Technology leader (TL DF) ${ }^{*}$

Technology leader (TL NDF) ${ }^{*}$

Count subfields of prior experience

(CFPE)

Count subfields of prior experience in disconnected subfields (CFPE DF) ${ }^{*}$

Count subfields of prior experience in nondisconnected subfields (CFPE NDF) ${ }^{*}$

Technology leadership 1 subfield (CFTL 1)

Technology leadership in at least 2 subfields (CFTL >1)

Technology leadership 1 disconnected subfield (CFTL DF 1)

Technology leadership in at least 2 disconnected subfields (CFTL DF $>1$ )

Technology leadership 1 non-disconnected subfield (CFTL NDF 1)

Technology leadership in at least 2 nondisconnected subfields (CFTL NDF $>1$ )

Company scale

Company diversification

Team size

Inventor experience

Inventor diversification

External social capital

Count tech class

Potential tech. comb.

Non-pat. cit.

Back. cit.

Technology dummies

Year dummies
Dependent Dummy indicating the patent combines at least 2 disconnected technology subclasses for the first time in history

Dependent Dummy indicating the patent combines at least 2 disconnected technology subclasses and has a high impact on future patents (see appendix 1 for the identification of high impact patents)

Independent Dummy indicating the assigned company has filed prior patents in the same technology subclass(es) as the focal patent

Independent Dummy indicating the assigned company has filed prior patents in the disconnected technology subclass(es) of the focal patent, which is/are combined for the first time in history

Independent Dummy indicating the assigned company has filed prior patents in the non-disconnected technology subclass(es) of the focal patent, which are not combined for the first time

Independent Dummy indicating the assigned company is among the top 5\% of all assignees filing patents in the same technology subclass(es) in the same year as the focal patent in terms of the count of prior patents filed in the same subclass(es) (see figure 2 for an illustration for a particular subclass and application year)

Independent Dummy indicating the assigned company is technology leader (TL) in the disconnected technology subclass(es) of the focal patent, which is/are combined for the first time in history

Independent Dummy indicating the assigned company is technology leader (TL) in the non-disconnected subclass(es) of the focal patent

Independent Ln count of the patent's technology subclass(es) in which the assigned company has patented before

Independent Ln count of the patent's disconnected technology subclass(es) in which the assigned company has patented before

Independent Ln count of the patent's non-disconnected technology subclass(es) in which the assigned company has patented before

Independent Dummy indicating the assigned company is technology leader (TL) in 1 technology subclass of the focal patent

Independent Dummy indicating the assigned company is technology leader (TL) in at least 2 technology subclasses of the focal patent

Independent Dummy indicating the assigned company is technology leader (TL) in 1 disconnected technology subclass of the focal patent, , which is combined for the first time in history

Independent Dummy indicating the assigned company is technology leader (TL) in at least 2 disconnected technology subclasses of the focal patent, which is/are combined for the first time in history

Independent Dummy indicating the assigned company is technology leader (TL) in 1 non-disconnected technology subclass of the focal patent

Independent Dummy indicating the assigned company is technology leader (TL) in at least 2 non-disconnected technology subclasses of the focal patent

Control Ln count of a company's prior patents

Control 1- bias-corrected Herfindahl index of technology class specialization (main class), based on the count of prior patents filed in each class (Hall et al, 2000)

Control Ln count of inventors

Control Ln average of team members' count of prior patents

Control The average of team member's technology diversification, measured as 1- bias-corrected Herfindahl index of technology class specialization (main class), based on the count of patents filed in each class (see Hall et al, 2000)

Control Ln count of unique co-inventors on the inventors' previous patents, excluding the inventors themselves

Control Ln count of main classes (3 digit)

Control Ln count of pairwise combinations of technology subclasses, i.e. $\operatorname{Ln}\left[\frac{\text { Count technology subclasses! }}{2 ! \times(\text { Count technology subclasses }-2) !}\right]$

Control Ln count of non-technological prior art citations

Control Ln count of technological prior art citation

Control Dummies for each of a patent's main technology classes

Control Dummy for the application year of a patent

We added 1 for all count variables which had 0 values before taking the natural logarithm,

* only calculated for those patents which combine 2 disconnected technology subclasses 
Table 2: Descriptive Statistics for All Company-Assigned U.S. Granted Patents, Filed 1980-2001

\begin{tabular}{|c|c|c|c|c|c|c|c|c|c|c|}
\hline \multirow[b]{2}{*}{ Variable } & \multicolumn{5}{|c|}{ Full sample } & \multicolumn{5}{|c|}{ Compustat sample } \\
\hline & $\mathrm{n}$ & Mean & Stdev. & Min. & Max. & $\mathrm{n}$ & Mean & Stdev. & Min. & Max. \\
\hline New combination & $1,744,625$ & 0.53 & 0.50 & 0.00 & 1.00 & 754,615 & 0.53 & 0.50 & 0.00 & 1.00 \\
\hline High impact new combination & $1,744,625$ & 0.02 & 0.14 & 0.00 & 1.00 & 754,615 & 0.02 & 0.15 & 0.00 & 1.00 \\
\hline Company prior experience (PE) & $1,744,625$ & 0.68 & 0.47 & 0.00 & 1.00 & 754,615 & 0.84 & 0.37 & 0.00 & 1.00 \\
\hline Company prior experience in disconnected subfield(s) (PE DF) & 925,980 & 0.63 & 0.48 & 0.00 & 1.00 & 401,949 & 0.79 & 0.40 & 0.00 & 1.00 \\
\hline Company prior experience in non-disconnected subfield(s) (PE NDF) & 925,980 & 0.30 & 0.46 & 0.00 & 1.00 & 401,949 & 0.38 & 0.49 & 0.00 & 1.00 \\
\hline Technology leader (TL) & $1,744,625$ & 0.07 & 0.26 & 0.00 & 1.00 & 754,615 & 0.14 & 0.34 & 0.00 & 1.00 \\
\hline Technology leader in disconnected subfield(s) (TL DF) & 925,980 & 0.05 & 0.21 & 0.00 & 1.00 & 401,949 & 0.09 & 0.29 & 0.00 & 1.00 \\
\hline Technology leader in non-disconnected subfield(s) (TL NDF) & 925,980 & 0.03 & 0.17 & 0.00 & 1.00 & 401,949 & 0.06 & 0.24 & 0.00 & 1.00 \\
\hline Count subfields of prior experience (CFPE) & $1,744,625$ & 0.90 & 0.74 & 0.00 & 5.04 & 754,615 & 1.16 & 0.68 & 0.00 & 5.01 \\
\hline Count subfields of prior experience in disconnected subfield(s) (CFPE DF) & 925,980 & 0.77 & 0.72 & 0.00 & 5.04 & 401,949 & 1.02 & 0.69 & 0.00 & 5.01 \\
\hline Count subfields of prior experience in non-disconnected subfield(s) (CFPE NDF) & 925,980 & 0.31 & 0.52 & 0.00 & 3.91 & 401,949 & 0.40 & 0.57 & 0.00 & 3.91 \\
\hline Technology leadership in 1 subfield (CFTL 1) & $1,744,625$ & 0.04 & 0.20 & 0.00 & 1.00 & 754,615 & 0.07 & 0.26 & 0.00 & 1.00 \\
\hline Technology leadership in more than 1 subfield (CFTL >1) & $1,744,625$ & 0.03 & 0.17 & 0.00 & 1.00 & 754,615 & 0.06 & 0.24 & 0.00 & 1.00 \\
\hline Technology leadership in 1 disconnected subfield(s) (CFTL DF 1) & 925,980 & 0.03 & 0.18 & 0.00 & 1.00 & 401,949 & 0.06 & 0.24 & 0.00 & 1.00 \\
\hline Technology leadership in more than 1 disconnected subfield(s) (CFTL DF >1) & 925,980 & 0.02 & 0.12 & 0.00 & 1.00 & 401,949 & 0.03 & 0.17 & 0.00 & 1.00 \\
\hline Technology leadership in 1 non-disconnected subfield(s) (CFTL NDF 1) & 925,980 & 0.02 & 0.14 & 0.00 & 1.00 & 401,949 & 0.04 & 0.19 & 0.00 & 1.00 \\
\hline Technology leadership in more than 1 non-disconnected subfield(s) (CFTL NDF >1) & 925,980 & 0.01 & 0.10 & 0.00 & 1.00 & 401,949 & 0.02 & 0.14 & 0.00 & 1.00 \\
\hline Company scale & $1,744,625$ & 5.12 & 3.05 & 0.00 & 10.69 & 754,615 & 7.10 & 2.27 & 0.00 & 10.50 \\
\hline Company diversification & $1,744,625$ & 0.72 & 0.34 & 0.00 & 0.99 & 754,615 & 0.91 & 0.18 & 0.00 & 0.99 \\
\hline Team size & $1,744,625$ & 0.66 & 0.60 & 0.00 & 3.93 & 754,615 & 0.70 & 0.61 & 0.00 & 3.93 \\
\hline Inventor experience & $1,744,625$ & 1.43 & 1.12 & 0.00 & 7.05 & 754611 & 1.59 & 1.12 & 0.00 & 6.11 \\
\hline Inventor diversification & $1,744,625$ & 0.65 & 0.39 & 0.00 & 1.00 & 754,615 & 0.70 & 0.37 & 0.00 & 1.00 \\
\hline Social capital & $1,744,625$ & 1.60 & 1.36 & 0.00 & 6.65 & 754,615 & 1.86 & 1.37 & 0.00 & 6.65 \\
\hline Count tech class & $1,744,625$ & 0.49 & 0.48 & 0.00 & 2.56 & 754,615 & 0.50 & 0.48 & 0.00 & 2.48 \\
\hline Potential tech. comb. & $1,744,625$ & 1.96 & 1.06 & 0.00 & 9.57 & 754,615 & 1.99 & 1.07 & 0.00 & 9.55 \\
\hline Non-pat. cit. & $1,744,625$ & 0.60 & 0.99 & 0.00 & 6.98 & 754,615 & 0.69 & 1.03 & 0.00 & 6.98 \\
\hline Back. cit. & $1,744,625$ & 2.02 & 0.80 & 0.00 & 6.65 & 754,615 & 2.08 & 0.81 & 0.00 & 6.65 \\
\hline
\end{tabular}


Table 3: Correlation Matrix for All Company-Assigned U.S. Granted Patents,

Filed 1980-2001 (n=1,744,625)

\begin{tabular}{|c|c|c|c|c|c|c|c|c|c|c|c|c|c|c|c|c|c|c|c|c|c|c|c|c|c|c|c|c|}
\hline & & (1) & (2) & (3) & (4) & $(5)$ & (6) & (7) & $(8)$ & (9) & (10) & (11) & (12) & (13) & (14) & (15) & (16) & (17) & (18) & (19) & (20) & (21) & (22) & (23) & (24) & (25) & (26) & (27) \\
\hline (1) & New combi & 1.00 & & & & & & & & & & & & & & & & & & & & & & & & & & \\
\hline (2) & $\begin{array}{l}\text { High impact } \\
\text { new combi }\end{array}$ & 0.13 & 1.00 & & & & & & & & & & & & & & & & & & & & & & & & & \\
\hline (3) & $\mathrm{PE}$ & -0.04 & 0.01 & 1.00 & & & & & & & & & & & & & & & & & & & & & & & & \\
\hline (4) & PE DF & . & 0.02 & 0.92 & 1.00 & & & & & & & & & & & & & & & & & & & & & & & \\
\hline (5) & PE NDF & . & 0.01 & 0.46 & 0.34 & 1.00 & & & & & & & & & & & & & & & & & & & & & & \\
\hline (6) & $\mathrm{TL}$ & -0.02 & 0.01 & 0.19 & 0.20 & 0.20 & 1.00 & & & & & & & & & & & & & & & & & & & & & \\
\hline (7) & TL DF & & 0.02 & 0.16 & 0.17 & 0.10 & 0.84 & 1.00 & & & & & & & & & & & & & & & & & & & & \\
\hline (8) & TL NDF & . & 0.01 & 0.13 & 0.13 & 0.27 & 0.67 & 0.31 & 1.00 & & & & & & & & & & & & & & & & & & & \\
\hline (9) & CFPE & 0.04 & 0.03 & 0.84 & 0.81 & 0.55 & 0.31 & 0.28 & 0.24 & 1.00 & & & & & & & & & & & & & & & & & & \\
\hline (10) & CFPE DF & . & 0.04 & 0.76 & 0.83 & 0.27 & 0.30 & 0.30 & 0.16 & 0.93 & 1.00 & & & & & & & & & & & & & & & & & \\
\hline (11) & CFPE NDF & . & 0.01 & 0.42 & 0.32 & 0.90 & 0.25 & 0.12 & 0.35 & 0.59 & 0.28 & 1.00 & & & & & & & & & & & & & & & & \\
\hline (12) & CFTL 1 & -0.01 & 0.01 & 0.14 & 0.15 & 0.13 & 0.74 & 0.56 & 0.36 & 0.20 & 0.20 & 0.14 & 1.00 & & & & & & & & & & & & & & & \\
\hline (13) & CFTL $>1$ & -0.02 & 0.00 & 0.12 & 0.13 & 0.15 & 0.65 & 0.62 & 0.59 & 0.24 & 0.22 & 0.21 & -0.04 & 1.00 & & & & & & & & & & & & & & \\
\hline (14) & CFTL DF 1 & . & 0.01 & 0.13 & 0.14 & 0.09 & 0.69 & 0.82 & 0.22 & 0.21 & 0.21 & 0.10 & 0.69 & 0.23 & 1.00 & & & & & & & & & & & & & \\
\hline (15) & CFTL DF $>1$ & & 0.01 & 0.09 & 0.10 & 0.05 & 0.47 & 0.56 & 0.22 & 0.19 & 0.21 & 0.06 & -0.02 & 0.74 & -0.02 & 1.00 & & & & & & & & & & & & \\
\hline (16) & CFTL NDF 1 & . & 0.01 & 0.10 & 0.10 & 0.22 & 0.54 & 0.21 & 0.81 & 0.17 & 0.12 & 0.24 & 0.46 & 0.28 & 0.16 & 0.14 & 1.00 & & & & & & & & & & & \\
\hline (17) & CFTL NDF $>1$ & . & 0.00 & 0.07 & 0.08 & 0.16 & 0.39 & 0.23 & 0.58 & 0.16 & 0.09 & 0.27 & -0.02 & 0.61 & 0.15 & 0.18 & -0.01 & 1.00 & & & & & & & & & & \\
\hline (18) & Company scale & -0.02 & -0.01 & 0.56 & 0.57 & 0.31 & 0.28 & 0.24 & 0.19 & 0.58 & 0.58 & 0.30 & 0.19 & 0.20 & 0.19 & 0.15 & 0.15 & 0.11 & 1.00 & & & & & & & & & \\
\hline (19) & Company div. & 0.00 & -0.01 & 0.48 & 0.48 & 0.24 & 0.14 & 0.13 & 0.10 & 0.45 & 0.45 & 0.23 & 0.10 & 0.09 & 0.10 & 0.08 & 0.08 & 0.05 & 0.82 & 1.00 & & & & & & & & \\
\hline (20) & Team size & -0.01 & 0.03 & 0.12 & 0.12 & 0.09 & 0.08 & 0.07 & 0.06 & 0.15 & 0.15 & 0.11 & 0.05 & 0.07 & 0.05 & 0.05 & 0.05 & 0.04 & 0.15 & 0.14 & 1.00 & & & & & & & \\
\hline (21) & Inventor experience & -0.05 & 0.01 & 0.31 & 0.30 & 0.21 & 0.16 & 0.13 & 0.12 & 0.35 & 0.33 & 0.22 & 0.11 & 0.12 & 0.10 & 0.08 & 0.09 & 0.09 & 0.28 & 0.21 & 0.12 & 1.00 & & & & & & \\
\hline (22) & Inventor div. & -0.04 & 0.01 & 0.28 & 0.27 & 0.17 & 0.09 & 0.07 & 0.07 & 0.29 & 0.27 & 0.18 & 0.06 & 0.06 & 0.06 & 0.04 & 0.05 & 0.04 & 0.20 & 0.17 & -0.01 & 0.71 & 1.00 & & & & & \\
\hline (23) & Social capital & -0.05 & 0.02 & 0.31 & 0.31 & 0.22 & 0.19 & 0.16 & 0.14 & 0.36 & 0.35 & 0.24 & 0.13 & 0.14 & 0.12 & 0.10 & 0.10 & 0.10 & 0.38 & 0.29 & 0.50 & 0.77 & 0.52 & 1.00 & & & & \\
\hline (24) & Count tech class & 0.41 & 0.11 & 0.04 & 0.09 & -0.07 & 0.06 & 0.08 & 0.01 & 0.16 & 0.20 & -0.05 & 0.03 & 0.05 & 0.05 & 0.07 & 0.00 & 0.01 & -0.01 & 0.02 & 0.04 & 0.01 & 0.01 & 0.02 & 1.00 & & & \\
\hline (25) & Potential tech. comb. & 0.47 & 0.11 & 0.11 & 0.17 & 0.15 & 0.12 & 0.13 & 0.10 & 0.40 & 0.41 & 0.25 & 0.05 & 0.13 & 0.07 & 0.12 & 0.06 & 0.10 & 0.03 & 0.03 & 0.09 & 0.07 & 0.05 & 0.09 & 0.50 & 1.00 & & \\
\hline (26) & Non-pat. cit. & 0.00 & 0.05 & 0.05 & 0.06 & 0.05 & 0.09 & 0.06 & 0.05 & 0.10 & 0.09 & 0.07 & 0.05 & 0.08 & 0.04 & 0.04 & 0.04 & 0.04 & 0.02 & 0.01 & 0.14 & 0.07 & 0.04 & 0.11 & 0.09 & 0.12 & 1.00 & \\
\hline (27) & Back. cit. & 0.03 & 0.07 & 0.00 & 0.00 & 0.01 & 0.03 & 0.04 & 0.02 & 0.02 & 0.01 & 0.01 & 0.02 & 0.02 & 0.02 & 0.03 & 0.02 & 0.02 & -0.07 & -0.07 & 0.00 & 0.06 & 0.05 & 0.02 & 0.03 & 0.06 & 0.14 & 1.00 \\
\hline
\end{tabular}


Table 4: Probit Selection Model All Company-Assigned U.S. Granted Patents, Filed 1980-2001 $(n=1,744,625)$

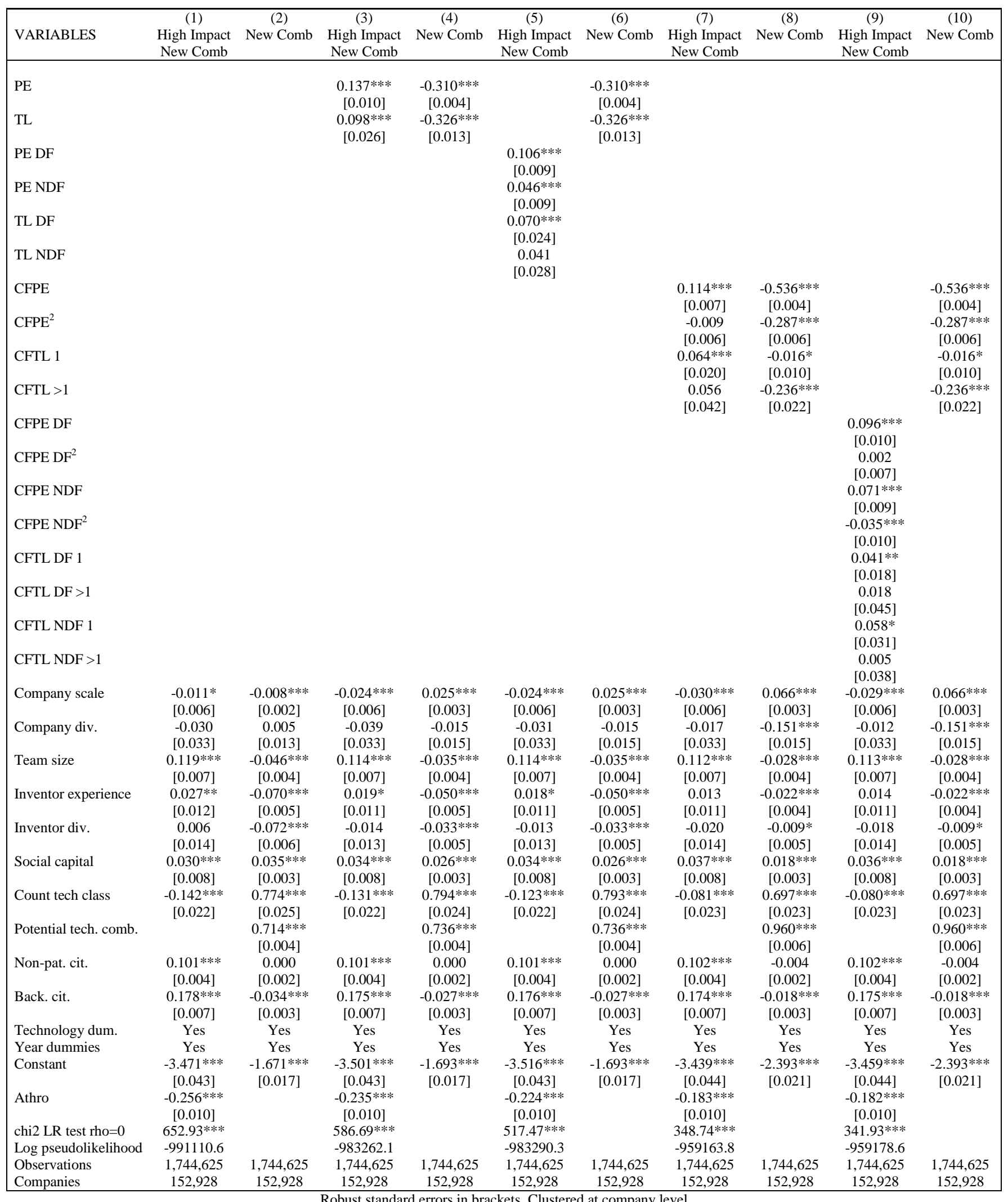

Robust standard errors in brackets, Clustered at company level

$* * * \mathrm{p}<0.01, * * \mathrm{p}<0.05, * \mathrm{p}<0.1$ 
Table 5: Probit Selection Model US Compustat Company-Assigned U.S. Granted Patents, Filed 1980-2001 $(n=754,611)$

\begin{tabular}{|c|c|c|c|c|c|c|c|c|}
\hline VARIABLES & $\begin{array}{c}\text { (1) } \\
\text { High Impact } \\
\text { New Comb }\end{array}$ & $\begin{array}{c}\text { (2) } \\
\text { New Comb }\end{array}$ & $\begin{array}{c}(3) \\
\text { High Impact } \\
\text { New Comb }\end{array}$ & $\begin{array}{c}\text { (4) } \\
\text { New Comb }\end{array}$ & $\begin{array}{c}(5) \\
\text { High Impact } \\
\text { New Comb }\end{array}$ & $\begin{array}{c}(6) \\
\text { New Comb }\end{array}$ & $\begin{array}{c}\text { (7) } \\
\text { High Impact } \\
\text { New Comb }\end{array}$ & $\begin{array}{c}(8) \\
\text { New Comb }\end{array}$ \\
\hline PE & $\begin{array}{c}0.093 * * * \\
{[0.017]}\end{array}$ & $\begin{array}{c}-0.272 * * * \\
{[0.007]}\end{array}$ & & $\begin{array}{c}-0.271 * * * \\
{[0.007]}\end{array}$ & & & & \\
\hline TL & $\begin{array}{c}0.081 * * * \\
{[0.025]}\end{array}$ & $\begin{array}{c}-0.313 * * * \\
{[0.013]}\end{array}$ & & $\begin{array}{c}-0.313 * * * \\
{[0.013]}\end{array}$ & & & & \\
\hline PE DF & & & $\begin{array}{c}0.063 * * * \\
{[0.015]}\end{array}$ & & & & & \\
\hline PE NDF & & & $\begin{array}{c}0.023 * * \\
{[0.011]}\end{array}$ & & & & & \\
\hline TL DF & & & $\begin{array}{c}0.064 * * * \\
{[0.023]}\end{array}$ & & & & & \\
\hline TL NDF & & & $\begin{array}{c}0.039 \\
{[0.029]}\end{array}$ & & & & & \\
\hline CFPE & & & & & $\begin{array}{c}0.087 * * * \\
{[0.011]}\end{array}$ & $\begin{array}{c}-0.679 * * * \\
{[0.013]}\end{array}$ & & $\begin{array}{c}-0.679 * * * \\
{[0.013]}\end{array}$ \\
\hline $\mathrm{CFPE}^{2}$ & & & & & $\begin{array}{c}0.008 \\
{[0.008]}\end{array}$ & $\begin{array}{c}-0.311 * * * \\
{[0.009]}\end{array}$ & & $\begin{array}{c}-0.311 * * * \\
{[0.009]}\end{array}$ \\
\hline CFTL 1 & & & & & $\begin{array}{c}0.043 * * \\
{[0.022]}\end{array}$ & $\begin{array}{c}-0.033 * * * \\
{[0.010]}\end{array}$ & & $\begin{array}{c}-0.033 * * * \\
{[0.010]}\end{array}$ \\
\hline CFTL $>1$ & & & & & $\begin{array}{c}0.050 \\
{[0.039]}\end{array}$ & $\begin{array}{c}-0.268 * * * \\
{[0.023]}\end{array}$ & & $\begin{array}{c}-0.268 * * * \\
{[0.023]}\end{array}$ \\
\hline CFPE DF & & & & & & & $\begin{array}{c}0.079 * * * \\
{[0.011]}\end{array}$ & \\
\hline CFPE DF $^{2}$ & & & & & & & $\begin{array}{c}0.023 * * * \\
{[0.008]}\end{array}$ & \\
\hline CFPE NDF & & & & & & & $\begin{array}{c}0.054 * * * \\
{[0.014]}\end{array}$ & \\
\hline CFPE NDF $^{2}$ & & & & & & & $\begin{array}{c}-0.025 * * \\
{[0.013]}\end{array}$ & \\
\hline CFTL DF 1 & & & & & & & $\begin{array}{c}0.033 \\
{[0.021]}\end{array}$ & \\
\hline CFTL DF $>1$ & & & & & & & $\begin{array}{c}0.012 \\
{[0.039]}\end{array}$ & \\
\hline CFTL NDF 1 & & & & & & & $\begin{array}{l}0.063 * \\
{[0.033]}\end{array}$ & \\
\hline CFTL NDF $>1$ & & & & & & & $\begin{array}{c}0.003 \\
{[0.034]}\end{array}$ & \\
\hline Company scale & $\begin{array}{c}-0.038 * * * \\
{[0.008]}\end{array}$ & $\begin{array}{c}0.027 * * * \\
{[0.005]}\end{array}$ & $\begin{array}{c}-0.037 * * * \\
{[0.008]}\end{array}$ & $\begin{array}{c}0.027 * * * \\
{[0.005]}\end{array}$ & $\begin{array}{c}-0.042 * * * \\
{[0.008]}\end{array}$ & $\begin{array}{c}0.061 * * * \\
{[0.006]}\end{array}$ & $\begin{array}{c}-0.041 * * * \\
{[0.008]}\end{array}$ & $\begin{array}{c}0.061 * * * \\
{[0.006]}\end{array}$ \\
\hline Company div. & $\begin{array}{c}0.052 \\
{[0.063]}\end{array}$ & $\begin{array}{c}-0.086 * * \\
{[0.037]}\end{array}$ & $\begin{array}{c}0.051 \\
{[0.063]}\end{array}$ & $\begin{array}{c}-0.086 * * \\
{[0.037]}\end{array}$ & $\begin{array}{c}0.072 \\
{[0.063]}\end{array}$ & $\begin{array}{c}-0.251 * * * \\
{[0.042]}\end{array}$ & $\begin{array}{c}0.071 \\
{[0.064]}\end{array}$ & $\begin{array}{c}-0.250 * * * \\
{[0.042]}\end{array}$ \\
\hline Team size & $\begin{array}{c}0.107 * * * \\
{[0.011]}\end{array}$ & $\begin{array}{c}-0.041 * * * \\
{[0.006]}\end{array}$ & $\begin{array}{c}0.107 * * * \\
{[0.011]}\end{array}$ & $\begin{array}{c}-0.041 * * * \\
{[0.006]}\end{array}$ & $\begin{array}{c}0.105 * * * \\
{[0.011]}\end{array}$ & $\begin{array}{c}-0.034 * * * \\
{[0.006]}\end{array}$ & $\begin{array}{c}0.105^{* * *} * \\
{[0.011]}\end{array}$ & $\begin{array}{c}-0.034 * * * \\
{[0.006]}\end{array}$ \\
\hline Inventor experience & $\begin{array}{c}0.014 \\
{[0.022]}\end{array}$ & $\begin{array}{c}-0.067 * * * \\
{[0.007]}\end{array}$ & $\begin{array}{c}0.014 \\
{[0.022]}\end{array}$ & $\begin{array}{c}-0.067 * * * \\
{[0.007]}\end{array}$ & $\begin{array}{c}0.008 \\
{[0.022]}\end{array}$ & $\begin{array}{c}-0.041 * * * \\
{[0.007]}\end{array}$ & $\begin{array}{c}0.009 \\
{[0.022]}\end{array}$ & $\begin{array}{c}-0.041 * * * \\
{[0.007]}\end{array}$ \\
\hline Inventor div. & $\begin{array}{l}-0.041 * \\
{[0.023]}\end{array}$ & $\begin{array}{c}-0.049 * * * \\
{[0.008]}\end{array}$ & $\begin{array}{l}-0.040 * \\
{[0.023]}\end{array}$ & $\begin{array}{c}-0.049 * * * \\
{[0.008]}\end{array}$ & $\begin{array}{c}-0.048 * * \\
{[0.023]}\end{array}$ & $\begin{array}{c}-0.025 * * * \\
{[0.009]}\end{array}$ & $\begin{array}{c}-0.046^{* *} \\
{[0.023]}\end{array}$ & $\begin{array}{c}-0.025 * * * \\
{[0.009]}\end{array}$ \\
\hline Social capital & $\begin{array}{c}0.041 * * * \\
{[0.015]}\end{array}$ & $\begin{array}{c}0.051 * * * \\
{[0.006]}\end{array}$ & $\begin{array}{c}0.042^{* * *} * \\
{[0.015]}\end{array}$ & $\begin{array}{c}0.051 * * * \\
{[0.006]}\end{array}$ & $\begin{array}{c}0.043 * * * \\
{[0.015]}\end{array}$ & $\begin{array}{c}0.048 * * * \\
{[0.006]}\end{array}$ & $\begin{array}{c}0.043^{* * * *} \\
{[0.015]}\end{array}$ & $\begin{array}{c}0.048 * * * \\
{[0.006]}\end{array}$ \\
\hline Count tech class & $\begin{array}{c}-0.134 * * * \\
{[0.034]}\end{array}$ & $\begin{array}{c}0.755 * * * \\
{[0.041]}\end{array}$ & $\begin{array}{c}-0.129 * * * \\
{[0.034]}\end{array}$ & $\begin{array}{c}0.755^{*} * * \\
{[0.041]}\end{array}$ & $\begin{array}{c}-0.072 * * \\
{[0.036]}\end{array}$ & $\begin{array}{c}0.654 * * * \\
{[0.041]}\end{array}$ & $\begin{array}{c}-0.067 * \\
{[0.036]}\end{array}$ & $\begin{array}{c}0.654 * * * \\
{[0.041]}\end{array}$ \\
\hline Potential tech. comb. & & $\begin{array}{c}0.713^{* * *} * \\
{[0.008]}\end{array}$ & & $\begin{array}{c}0.713 * * * \\
{[0.008]}\end{array}$ & & $\begin{array}{c}1.006 * * * \\
{[0.012]}\end{array}$ & & $\begin{array}{c}1.006 * * * \\
{[0.012]}\end{array}$ \\
\hline Non-pat. cit. & $\begin{array}{c}0.098 * * * \\
{[0.006]}\end{array}$ & $\begin{array}{c}-0.000 \\
{[0.004]}\end{array}$ & $\begin{array}{c}0.098 * * * \\
{[0.006]}\end{array}$ & $\begin{array}{c}-0.000 \\
{[0.004]}\end{array}$ & $\begin{array}{c}0.099 * * * \\
{[0.006]}\end{array}$ & $\begin{array}{c}-0.004 \\
{[0.004]}\end{array}$ & $\begin{array}{c}0.099 * * * \\
{[0.006]}\end{array}$ & $\begin{array}{c}-0.004 \\
{[0.004]}\end{array}$ \\
\hline Back. cit. & $\begin{array}{c}0.133 * * * \\
{[0.011]}\end{array}$ & $\begin{array}{c}-0.023 * * * \\
{[0.005]}\end{array}$ & $\begin{array}{c}0.133 * * * \\
{[0.011]}\end{array}$ & $\begin{array}{c}-0.023 * * * \\
{[0.005]}\end{array}$ & $\begin{array}{c}0.132 * * * \\
{[0.011]}\end{array}$ & $\begin{array}{c}-0.019 * * * \\
{[0.005]}\end{array}$ & $\begin{array}{c}0.133 * * * \\
{[0.011]}\end{array}$ & $\begin{array}{c}-0.019 * * * \\
{[0.005]}\end{array}$ \\
\hline $\begin{array}{l}\text { Technology dum. } \\
\text { Year dummies }\end{array}$ & $\begin{array}{l}\text { Yes } \\
\text { Yes }\end{array}$ & $\begin{array}{l}\text { Yes } \\
\text { Yes }\end{array}$ & $\begin{array}{l}\text { Yes } \\
\text { Yes }\end{array}$ & $\begin{array}{l}\text { Yes } \\
\text { Yes }\end{array}$ & $\begin{array}{l}\text { Yes } \\
\text { Yes }\end{array}$ & $\begin{array}{l}\text { Yes } \\
\text { Yes }\end{array}$ & $\begin{array}{l}\text { Yes } \\
\text { Yes }\end{array}$ & $\begin{array}{l}\text { Yes } \\
\text { Yes }\end{array}$ \\
\hline Constant & $\begin{array}{c}-3.299 * * * \\
{[0.074]}\end{array}$ & $\begin{array}{c}-1.717 * * * \\
{[0.034]}\end{array}$ & $\begin{array}{c}-3.300^{* * * *} \\
{[0.074]}\end{array}$ & $\begin{array}{c}-1.717 * * * \\
{[0.034]}\end{array}$ & $\begin{array}{c}-3.272 * * * \\
{[0.076]}\end{array}$ & $\begin{array}{c}-2.588 * * * \\
{[0.043]}\end{array}$ & $\begin{array}{c}-3.270 * * * \\
{[0.076]}\end{array}$ & $\begin{array}{c}-2.588 * * * \\
{[0.043]}\end{array}$ \\
\hline Athro & $\begin{array}{c}-0.221 * * * \\
{[0.014]}\end{array}$ & & $\begin{array}{c}-0.214 * * * \\
{[0.014]}\end{array}$ & & $\begin{array}{c}-0.157 * * * \\
{[0.015]}\end{array}$ & & $\begin{array}{c}-0.155 * * * \\
{[0.015]}\end{array}$ & \\
\hline chi2 LR test rho $=0$ & $265.51 * * *$ & & $237.62 * * *$ & & $108.16^{* * *}$ & & $104.49 * * *$ & \\
\hline Log pseudolikelihood & -431843.8 & & -431857.9 & & -421101.3 & & -421098.5 & \\
\hline Observations & 754,611 & 754,611 & 754,611 & 754,611 & 754,611 & 754,611 & 754,611 & 754,611 \\
\hline Companies & 5,421 & 5,421 & 5,421 & 5,421 & 5,421 & 5,421 & 5,421 & 5,421 \\
\hline
\end{tabular}

Robust standard errors in brackets, Clustered at company level

*** $\mathrm{p}<0.01, * * \mathrm{p}<0.05, * \mathrm{p}<0.1$ 
Table 6: Propensity Score Matching Technology Leader

\begin{tabular}{|c|c|c|c|c|c|c|c|c|c|c|c|c|c|}
\hline \multirow[b]{3}{*}{ Variable } & \multirow[b]{3}{*}{ Treatment } & \multirow[b]{3}{*}{ Sample } & & \multicolumn{5}{|c|}{ Full sample } & \multicolumn{5}{|c|}{ Compustat sample } \\
\hline & & & & \multicolumn{3}{|c|}{ Mean } & \multicolumn{2}{|c|}{ Paired t-test } & \multicolumn{3}{|c|}{ Mean } & \multicolumn{2}{|c|}{ Paired t-test } \\
\hline & & & & Treated & Control & Diff & $|t|$ & $p>|t|$ & Treated & Control & Diff & $|t|$ & $p>|t|$ \\
\hline \multirow[t]{2}{*}{ New Comb } & $\mathrm{TL}$ & Full & Unmatched & 0.4879 & 0.5340 & -0.0462 & -31.4381 & 0.0000 & 0.4931 & 0.5389 & -0.0458 & -27.3008 & 0.0000 \\
\hline & $\mathrm{TL}$ & Full & Matched & 0.4760 & 0.5733 & -0.0973 & -50.3256 & 0.0000 & 0.4795 & 0.5723 & -0.0929 & -43.9193 & 0.0000 \\
\hline \multirow[t]{2}{*}{ New Comb } & $\mathrm{TL}$ & $\mathrm{PE}=1$ & Unmatched & 0.4879 & 0.5193 & -0.0314 & -20.9537 & 0.0000 & 0.4931 & 0.5344 & -0.0413 & -24.2310 & 0.0000 \\
\hline & $\mathrm{TL}$ & $\mathrm{PE}=1$ & Matched & 0.4758 & 0.5668 & -0.0910 & -47.1316 & 0.0000 & 0.4791 & 0.5673 & -0.0882 & -41.6690 & 0.0000 \\
\hline \multirow[t]{2}{*}{ High Impact New Comb } & $\mathrm{TL}$ & New Combi $=1$ & Unmatched & 0.0496 & 0.0366 & 0.0130 & 16.3279 & 0.0000 & 0.0513 & 0.0422 & 0.0090 & 9.3143 & 0.0000 \\
\hline & TL & New Combi $=1$ & Matched & 0.0481 & 0.0377 & 0.0104 & 8.5576 & 0.0000 & 0.0479 & 0.0407 & 0.0072 & 5.3143 & 0.0000 \\
\hline \multirow[t]{2}{*}{ High Impact New Comb } & $\mathrm{TL}$ & New $C o m b i=1$ and $P E=1$ & Unmatched & 0.0496 & 0.0392 & 0.0104 & 12.3549 & 0.0000 & 0.0513 & 0.0437 & 0.0075 & 7.5401 & 0.0000 \\
\hline & TL & New Combi $=1$ and $P E=1$ & Matched & 0.0480 & 0.0374 & 0.0106 & 8.7496 & 0.0000 & 0.0478 & 0.0409 & 0.0069 & 5.0883 & 0.0000 \\
\hline \multirow[t]{2}{*}{ High Impact New Comb } & TL_DF & New Combi $=1$ & Unmatched & 0.0506 & 0.0367 & 0.0139 & 14.9342 & 0.0000 & 0.0526 & 0.0424 & 0.0102 & 9.1912 & 0.0000 \\
\hline & TL_DF & New Combi=1 & Matched & 0.0482 & 0.0435 & 0.0047 & 3.1946 & 0.0014 & 0.0498 & 0.0459 & 0.0039 & 2.3088 & 0.0210 \\
\hline \multirow[t]{2}{*}{ High Impact New Comb } & TL_DF & New Combi=1 and PE_DF=1 & Unmatched & 0.0506 & 0.0397 & 0.0109 & 11.1406 & 0.0000 & 0.0526 & 0.0440 & 0.0086 & 7.5130 & 0.0000 \\
\hline & TL_DF & New Combi $=1$ and PE_DF $=1$ & Matched & 0.0483 & 0.0426 & 0.0057 & 3.8274 & 0.0001 & 0.0498 & 0.0452 & 0.0046 & 2.6943 & 0.0071 \\
\hline
\end{tabular}




\section{Appendix 1: Example Reebok Pump Shoe Patent}

The Reebok pump shoe patent (\#5113599) was filed in 1990 by Reebok. The shoe was the first with an internal inflation mechanism regulating the fitting of the shoe. As can be seen in the patent description below, the invention was the first in history to cover both technology subclasses associated with boots, shoes and leggings as well as technology subclasses covering flexible bags with venting or ventilation means. As of November 2012, the patent has received 80 forward patent citations.

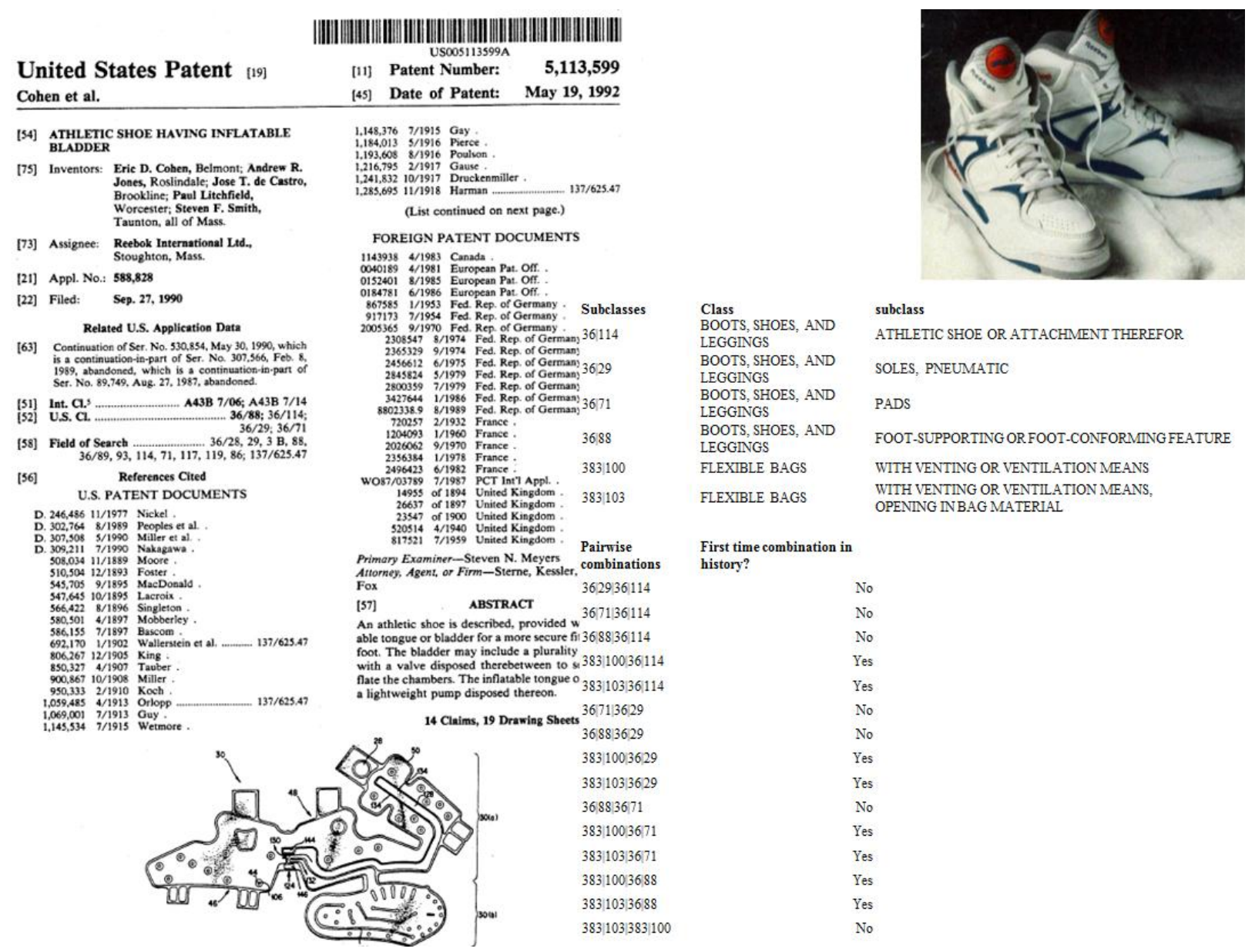




\section{Appendix 2: Identification of Patents with High Impact}

The count of forward citations a patent receives is related to its technological importance (Albert et al., 1991; Carpenter et al, 1993; Jaffe et al., 2000) as well as its social (Trajtenberg, 1990) and private value (Harhoff et al, 1999; Hall et al., 2005). The distribution of forward citations is very skewed with a large share of patents receiving no citations, i.e. technology dead ends, and a small minority of patents with a large number of forward citations. This pattern resembles the distribution of the actual value of inventions which is also very skewed. Therefore, it is most likely that outliers in the top of the distribution of forward citations pertain to most important technological inventions. To identify these outliers, we calculate for all granted US patents the count of forward citations as the number of patents citing the focal patent (patents granted in 2006 inclusive) and the truncated count of forward citations as the number of citations received within 5 years after application. Prior research has typically identified breakthrough patents as the top $1 \%$ or $5 \%$ in terms of forward citations compared to patents with the same application year and technology class (e.g. Ahuja and Lampert, 2001; Singh and Fleming, 2010). This definition assumes each technology field to have a fixed share of high impact inventions each year and does not compare patents across years. To avoid a definition that forces a fixed proportion of breakthroughs every year in each class while allowing similar patents to be compared across years, we look at the distribution of both forward citations received within 5 years and the distribution of forward citations received from all future patents until 2006. We use the full count of forward citations to compare all patents sharing at least one main technology class filed within the same year and the truncated citation count to compare all patents sharing at least one main technology class irrespectively of their time of filing. For each of the distributions, we calculate the mean and standard deviation of forward citation counts. Finally, a patent is labeled as having a big impact in case both its truncated and full count of forward citations are larger than the mean plus 2 times the standard deviation in at least one of its technology classes. So for each technology class of a patent, the patent is compared with 2 distributions, the distributions of full and truncated forward citation counts. 


\section{Appendix 3: Propensity Score Matching}

For TL and TL DF, we apply propensity score matching within groups of patent sharing the same technology class and application year. First, we estimate propensity scores using a probit model with the dependent variable being the dummy for treatment patent in function of the following variables: PE NDF, TL NDF, company scale, company diversification, team size, inventor experience, inventor skill diversification, social capital, count technology main classes, count technology subclasses, count non-patent references, count backward patent citations. Afterwards we run nearest neighbor matching with replacement and the restrictions that a treatment and matched control patent share the same technology class, application year and have a maximum difference in propensity score of 0.01 . Patents of technology leaders for which no matching control patent is found are excluded. We present our findings in table 6 as the average treatment effect on the treated. 